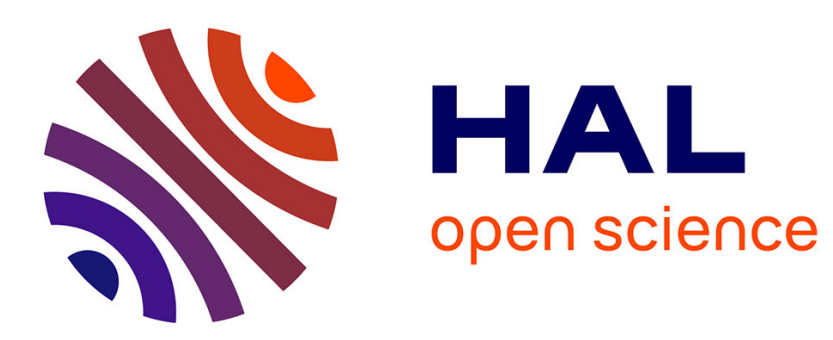

\title{
Intermittent Reinforcement and the Persistence of Behavior: Experimental Evidence
}

\author{
Robin M. Hogarth, Marie Claire Villeval
}

\section{To cite this version:}

Robin M. Hogarth, Marie Claire Villeval. Intermittent Reinforcement and the Persistence of Behavior: Experimental Evidence. 2010. halshs-00514125

HAL Id: halshs-00514125

https://shs.hal.science/halshs-00514125

Submitted on 1 Sep 2010

HAL is a multi-disciplinary open access archive for the deposit and dissemination of scientific research documents, whether they are published or not. The documents may come from teaching and research institutions in France or abroad, or from public or private research centers.
L'archive ouverte pluridisciplinaire HAL, est destinée au dépôt et à la diffusion de documents scientifiques de niveau recherche, publiés ou non, émanant des établissements d'enseignement et de recherche français ou étrangers, des laboratoires publics ou privés. 
Intermittent Reinforcement and the Persistence of Behavior: Experimental Evidence

Robin M. Hogarth, Marie-Claire Villeval

Juillet 2010 


\section{GATE Groupe d'Analyse et de Théorie Économique Lyon-St Étienne}

93, chemin des Mouilles 69130 Ecully - France

Tel. +33(0)4 72866060

Fax $+33(0) 472866090$

6, rue Basse des Rives 42023 Saint-Etienne cedex 02 - France

Tel. +33 (0)4 77421960

Fax. $+33(0) 477421950$

Messagerie électronique / Email : gate@gate.cnrs.fr

Téléchargement / Download : http://www.gate.cnrs.fr - Publications / Working Papers 


\title{
Intermittent Reinforcement and the Persistence of Behavior:
}

\author{
Experimental Evidence
}

Robin M. Hogarth and Marie Claire Villeval

July 30, 2010

\begin{abstract}
Whereas economists have made extensive studies of the impact of levels of incentives on behavior, they have paid little attention to the effects of regularity and frequency of incentives. We contrasted three ways of rewarding participants in a realeffort experiment in which individuals had to decide when to exit the situation: a continuous reinforcement schedule (all periods paid); a fixed intermittent reinforcement schedule (one out of three periods paid); and a random intermittent reinforcement schedule (one out of three periods paid on a random basis). In all treatments, monetary rewards were withdrawn after the same unknown number of periods. Overall, intermittent reinforcement leads to more persistence and higher total effort, while participants in the continuous condition exit as soon as payment stops or decrease effort dramatically. Randomness increases the dispersion of effort, inducing both early exiting and persistence in behavior; overall, it reduces agents' payoffs. Our interpretation is that, in the presence of regime shifts, both the frequency and the randomness of the reinforcement schedules influence adjustments that participants make across time to their reference points in earnings expectations. This could explain why agents persist in activities although they lose money, such as excess trading in stock markets.
\end{abstract}

Keywords: Intermittent reinforcement, ambiguity, randomness, incentives, experiment JEL Classifications: C92, M54, J28, J31

Contact: Robin M. Hogarth, ICREA, Department of Economics and Business, Universitat Pompeu Fabra, Ramon Trias Fargas, 25-27, 08005 Barcelona, Spain. E-mail: robin.hogarth@upf.edu

Marie Claire Villeval, University of Lyon, F-69007; CNRS-GATE, 93 Chemin des Mouilles, F-69130, Ecully, France; IZA, Bonn, Germany; CCP, Aarhus, Denmark. E-mail: villeval@gate.cnrs.fr

Acknowledgments: The authors are grateful for comments from David L. Dickinson, Dirk Engelmann, Lorenz Goette, Donald A. Hantula, Natalia Karelaia, Karl Schlag and participants at the World conference of the Economic Science Association in Copenhagen and at seminars at Universitat Pompeu Fabra and the University of Heidelberg. They also thank Romain Zeiliger for programming the experiment. Financial support from the Agence Nationale de la Recherche (ANR BLAN07-3_185547 "EMIR" project) is gratefully acknowledged. 


\section{INTRODUCTION}

In an intriguing paper, Odean (1999) asked: "Do investors trade too much?" His answer, based on studying trading in equity markets by investors with discount brokerage accounts was positive. Investors, one might assume, were overconfident? Perhaps, but it seems that some other factor was involved because the "result is more extreme than... predicted by overconfidence alone" (Odean, 1999, p. 1296).

The purpose of this paper is to draw attention to a possible behavioral explanation for why economic actors persist in activities that continue to lead to no gains or even losses. In addition to stock trading, these can include, for example, persisting in unprofitable investments in R \& D or marketing efforts, banks extending additional credit to customers with financial difficulties, or even some forms of gambling behavior. The situations that concern us are characterized by two structural features: first, they involve repeated activities across time; and second, there are one or more temporal regime shifts, i.e., the probabilities of the underlying system generating outcomes change. For example, the probability that a bank's customer is able to repay loans suddenly becomes lower.

When agents engage in repeated activities across time, economists typically assume that learning results from feedback and beliefs are updated in a Bayesian manner. However, there is little or no theoretical concern that the structure, as opposed to the informational content, of feedback might have effects. There is not even much awareness of this issue (for exceptions, see Lazear, 1990; 1991; O’Flaherty \& Komaki, 1992; Eriksson et al., 2009; Erev et al., 2010). In psychology, however, the effects of different types of feedback - or so-called reinforcement schedules - have been studied extensively for decades (see, e.g., Ferster \& Skinner, 1957).

Although there are many possible reinforcement schedules, it is useful to distinguish between two general types: continuous and intermittent (see, e.g., Hilgard \& Bower, 1975). 
Imagine a worker who is producing a series of widgets across time. With a continuous reinforcement schedule, the worker is rewarded for each trial (i.e., widget or batch of widgets) successfully completed. ${ }^{1}$ If, on the other hand, the worker is only rewarded periodically (say, once in three trials), the reinforcement schedule is intermittent. Moreover, this can be variable or fixed in nature. Variable means that trials are rewarded on a varying or random basis; fixed means that they are rewarded on a regular basis (e.g., every $3^{\text {rd }}$ trial).

Much research in psychology has examined the effects of learning by both humans and animals (rats and pigeons) under different reinforcement schedules. Of particular interest to the economic phenomena described above is what happens when there is a change in schedule, particularly when no further rewards are given (in a so-called extinction phase). The main result distinguishes situations where prior learning was reinforced by continuous as opposed to intermittent schedules. Given the former, the organism ceases the previously reinforced activity almost immediately. Given the latter, the organism persists in the activity that is no longer rewarded for some time, and particularly if learning has taken place under variable intermittent reinforcement. $^{2}$

It's not hard to make the link with different forms of economic activity. For most workers, monthly paychecks provide a form of continuous reinforcement and bonuses are experienced as intermittent. The thought of a possible bonus can be very motivating. For investment bankers, on the other hand, annual bonuses provide continuous reinforcement such that the failure to pay them can trigger exits. Trading in the stock market is also subject to variable intermittent reinforcement and many people clearly persist in the face of failure.

\footnotetext{
${ }^{1}$ Of course, the schedule where no trial ever gets rewarded is also "continuous."

${ }^{2}$ Hilgard \& Bower (1975) state "Responses trained on VI schedules are ... unusually resistant to extinction; it is not unusual, for instance, to observe pigeons responding more than 10,000 times during extinction following VI training. Resistance to extinction depends roughly on the mean and maximum interval in the VI program" (p. 215, VI for "variable intermittent").
} 
This paper investigates possible differential effects of continuous and intermittent reinforcement schedules in an economic context. Participants in a laboratory experiment were required to perform a task repeatedly and to decide when to exit the situation. As such, goal setting was endogenous. ${ }^{3}$ We compare three treatments in a between-subjects design. In the baseline treatment, participants were paid a piece-rate and each period gave rise to actual payment. This corresponds to a continuous reinforcement schedule. In the random intermittent reinforcement treatment, on average one period out of three was paid and the sequence of payments was random for each participant. In the fixed intermittent reinforcement treatment, one period out of three was paid according to a fixed schedule. In all three treatments, the $20^{\text {th }}$ period was paid but payment stopped thereafter. The participants were informed of the amount of the piece-rate but they received no ex ante information about the sequences of payments. They were only informed at the beginning of the session that some periods would be paid whereas others would not, and at the end of each period, whether it was paid or not. The environment we created in the laboratory is highly ambiguous and, since this could in itself affect decisions, we also elicited participants' risk attitude and ambiguity aversion.

Our findings indicate that in the baseline treatment participants generally exit soon after payment stops. On the other hand, participants in the random intermittent reinforcement treatment exit either before or long after payment stops, with the fixed intermittent reinforcement treatment in an intermediate position. Therefore, both the frequency and randomness of incentives matter in the decision to exit a situation. Moreover, when reinforcement is continuous, once payment stops individuals who do not exit immediately exert significantly lower effort than those under the other reinforcement schedules. Overall, intermittent reinforcement leads to more persistent behavior, higher

\footnotetext{
${ }^{3}$ See Locke and Latham (1990) for a review of goal setting in psychology.
} 
average effort levels, but lower payoffs for agents. This variation of effort across treatments after rewards cannot be rationalized by theories of income targeting (Camerer et al., 1997) but it is compatible with a theory of endogenous reference point determination based on expectations (Koszegi \& Rabin, 2007). We also find that risk aversion increases significantly the likelihood of early exit while, controlling for risk attitude, ambiguity aversion reduces it.

The remainder of the paper is organized as follows. Section 2 summarizes briefly the related literature in economics and psychology. Section 3 describes the experimental design. Section 4 presents the results of the study and section 5 concludes.

\section{RELATED LITERATURE}

Given the potential ubiquity of variable reinforcement schedules in economic life, it is surprising that economists have not been more concerned with their implications. Somewhat related to our analysis, some economic studies have investigated how affect and cognition influence the allocation of effort in reaction to changing incentives over time. However, this change is usually a variation in the level of compensation (see, e.g., Fehr \& Goette, 2007), not in its structure. For example, Camerer et al. (1997) have explored income targeting by cabdrivers to explain the negative response of hours worked to an increase in daily wages. Other studies have suggested that variations of motivation within a workday could explain this negative correlation (Goette et al., 2004). Goette and Huffman (2006) argue that the affective system reacts to within-day variations in earnings relative to an income target but once this is reached, the affective system does not react to earnings anymore. Based on a model of reference-dependent preferences with an endogenous reference point determination based on expectations, Koszegi and Rabin (2006) explain that workers are likely to stop working if the income earned thus far is unexpectedly high but 
will continue to work if expected income is high. Whereas these analyses could also potentially explain that individuals sometimes persist in efforts when incentives are removed (if expectations of earnings remain unaffected), they do not consider the influence of various continuous/intermittent reinforcement schedules on the endogenous determination of the reference point, and thus on the allocation of effort.

On the other hand, several investigations of variable reinforcement schedules have been conducted in applied psychology. For example, in a field study, Deslauriers and Everett (1977) showed how, to increase bus ridership, it was more effective to offer passengers variable as opposed to continuous reinforcement (gifting tokens to roughly every one in three passengers versus every passenger receiving a token). Golz (1992) pioneered an experimental game in which groups of participants could earn or lose money by investing under continuous and variable reinforcement conditions. In the acquisition phase, the market allowed participants to be successful; in the extinction phase, it did not. Participants exposed to continuous reinforcement in the acquisition phase invested much less in the extinction phase than those who experienced the variable reinforcement condition in the acquisition phase. Golz's paradigm has been extended in a series of studies by Hantula and his colleagues (Hantula \& Crowell, 1994; DeNicolis Bragger et al., 1998, 2003; Hantula \& DeNicolis Bragger, 1999; Brecher \& Hantula, 2005). ${ }^{4}$ The extensions involved different types of decision/investment scenarios, different levels of uncertainty in feedback, and different measures of decisions (information purchased, time to exit decisions, as well as amounts invested). All results show that variable reinforcement schedules induce responses that are more immune to extinction than their continuous counterparts.

\footnotetext{
${ }^{4}$ In clinical settings, psychologists have also studied whether intermittent vs. continuous schedules of reinforcement might increase the resistance of patients' problem behavior to extinction. See for example Lerman et al. (1996).
} 
By making different reinforcement schedules operational through returns having low and high variance (i.e., substituting for continuous as opposed variable schedules), Hantula and his colleagues opened the door to a further interpretation of persistence of behavior in the second phases of their experiments. Since feedback was not unequivocal (differing only between conditions on variance), it could be argued that, by investing more or delaying exit longer, participants were in fact dealing rationally with uncertainty. This view has been argued by Bowen (1987) in the management literature and is consistent with the observations of Dixit (1992) in economics. Bowen (1987) suggests that situations involving persistence should be viewed as decision dilemmas that managers handle by dealing with the uncertainties as they perceive them ex ante. It is not clear, therefore, that sticking to a particular commitment results from decision making errors. Dixit (1992) presents an economic analysis of situations where there might be a change in underlying circumstances (failures to invest in or to exit particular activities). There might be "a theory of optimal inertia" where "firms that refuse to invest even when the currently available rates of return are far in excess of the cost of capital may be optimally waiting to be surer that this state of affairs is not transitory. Likewise, farmers who carry large losses may be rationally keeping their operation alive on the chance that the future may be brighter" (Dixit, 1992, p. 109).

There is a closely related literature in management and social psychology on socalled escalation processes. These consider situations where an investment that went sour is nonetheless pursued and involves more losses across time (Staw, 1976; Staw \& Ross, 1989). Whereas some explanations point to cognitive errors such as the failure to understand sunk costs, others are motivational in nature and emphasize the realpolitik of organizational life. For example, Brockner (1992) has argued that, by continuing to invest in losing projects, people often engage in a process of self-justification. 
Last, in cognitive neuroscience, there is a related literature on reinforcement learning (Sutton \& Barto, 1998) and reward prediction error models of learning (Schultz et al., 1993; Montague et al., 1996). It has been shown in particular that, after repeated trials with a reward, the release of dopamine (a neurotransmitter involved in behavior and cognition) in the brain responds notably to the difference between received and expected reward. The omission of an expected reward induces a negative prediction error and a depression of the dopamine neurons. Dopamine neurons encode the prediction errors and signal the need to adjust behavior (for recent surveys on the neural basis of reinforcement learning, see Niv \& Montague, 2009, and Balleine et al., 2009).

In this paper, it is not our intention to adjudicate between cognitive or motivational explanations of behavior in the presence of continuous versus intermittent reinforcement schedules. Instead, we examine this phenomenon within a straightforward, economic context. We say "straightforward" because we wish to abstract from the myriad of possible organizational considerations; we say "economic" because most of the experimental evidence referred to above involved participants who did not face proper incentives. ${ }^{5}$

\section{EXPERIMENTAL DESIGN}

\subsection{Experimental treatments}

Our experiment consists of three different treatments and is based on a between-subjects design. In our baseline treatment, each participant has to perform a task that consists of counting the occurrence of four different letters in a paragraph. This task is repeated in different periods across time. In each period, a different paragraph is displayed on the participant's screen during two minutes. The paragraph consists of words that are randomly

\footnotetext{
${ }^{5}$ We are, of course, fully aware that if an experiment does not involve properly incentivized participants, it does not mean that its conclusions are necessarily invalid (Camerer \& Hogarth, 1999).
} 
combined to form four meaningless sentences. The letters to be counted appear successively. All the participants receive the same paragraphs and letters in the same order. The difficulty of the task is comparable across periods although the total number of words and letters in each line may differ since they are randomly displayed. An answer is considered correct if it corresponds to the true value plus or minus one. The participants are informed if a submitted answer is correct or not and the next letter is displayed. They are also continuously informed of the current number of their correct answers.

Participants are informed that they have to complete a minimum of 15 periods after which they are free to exit the situation. There is a maximum of 35 periods (i.e., 70 minutes) but this is not made common information. In other words, the participants can exit voluntarily between the $16^{\text {th }}$ and the $35^{\text {th }}$ periods. Participants are also informed that not all periods are paid but they do not know in advance whether a period will be paid or not. Nor are they informed about the total number of paying periods. At the end of each period, they are informed ex post whether correct answers provided in that period are or are not paid.

In the baseline treatment, all correct answers given in each of the first 20 periods are rewarded monetarily at the end of the session (i.e., when the participants have completed all experimental tasks). After the $20^{\text {th }}$ period, however, the correct answers no longer give rise to paying points. When periods are paid, each correct answer is rewarded with one paying point, such that between 0 and 4 points can be earned in a period. There is no penalty for providing wrong answers. It is also made common information that as soon as the participant decides to start a new period, he or she has to pay an entry fee of 1 point. This entry fee has to be paid whether correct answers are or are not paid in the period. Therefore, whereas payment of the entry fee is certain, the reward is uncertain.

To summarize, although participants have to enter the first fifteen periods of the task, this changes at the beginning of the sixteenth period. Now, before the beginning of a 
period, the participant must decide whether to start the period or not. If he or she starts the period, a new paragraph is displayed on the participant's screen during two minutes and four letters appear successively. Once the two minutes have elapsed, the participant is informed whether the period gives rise to payment or not. The screen also displays the total number of accumulated paying points. If the participant decides not to start a new period, he or she has to confirm this decision and exit the task.

The fixed intermittent reinforcement treatment is identical to the baseline treatment except that during the first 20 periods, one period out of three is paid (i.e., the $2^{\text {nd }}, 5^{\text {th }}, 8^{\text {th }}$, $11^{\text {th }}, 14^{\text {th }}, 17^{\text {th }}$, and the $20^{\text {th }}$ periods). In addition, in the paid periods each correct answer is rewarded by three paying points instead of one in the baseline treatment. ${ }^{6}$ Here too, no payment is made after the $20^{\text {th }}$ period (this is not common information).

The random intermittent reinforcement treatment is identical to the fixed intermittent reinforcement treatment (in particular, one period out of three is paid during the first 20 periods), except that the sequence of paid periods in the first 20 periods is randomly generated for each participant. Although sequences differ across participants, to facilitate comparisons between treatments, we impose the constraint that correct answers are paid for the $20^{\text {th }}$ period. As before, no more payment occurs after period 20. As in the fixed intermittent reinforcement treatment, correct answers are paid three times more than in the baseline treatment. In the three treatments, the same paragraphs appear in the same order to guarantee that the difficulty of the task is kept constant across treatments.

\footnotetext{
${ }^{6}$ In the baseline treatment, participants can earn a maximum of 80 paying points in the session (4 correct answers*1 point*20 paying periods), while in the two other treatments, the maximum is slightly higher, i.e., 84 ( 4 correct answers $* 3$ points $* 7$ paying periods). Therefore, the incentive to exert effort may be slightly higher in the intermittent reinforcement schedules. To make treatments identical on this point, we could have used a piece- rate of 2.86 instead of 3 in the intermittent reinforcement treatments. We reasoned, however, that this piece-rate would not be easily interpreted by the participants. In addition, since participants did not know in advance the sequence of payments, we do not believe that the difference we indicate has affected behavior.
} 
Comparing the baseline and the fixed intermittent reinforcement treatments helps to identify the impact of the frequency of rewards on exiting decisions, payoffs, and effort. Comparing the random intermittent reinforcement treatment with the two other treatments allows us to measure the impact of the randomness of rewards.

At the beginning of each experimental session, we elicited participants' attitudes toward risk and uncertainty by asking them to price both a clear and a vague bet following a procedure similar to that of Fox and Tversky (1995) (see Appendix A). The participants have to make a first set of 20 decisions between accepting a certain payoff and drawing a ball in an urn that contains 5 blue balls and 5 yellow balls (a risky lottery). The amount of the certain payoff increases from 0.25 Eurocents to 5 Euros. One yellow ball drawn from the urn pays $€ 5$, a blue ball pays nothing. Then, the participant has to make a second set of 20 similar decisions except that the proportions of yellow and blue balls in the urn are now unknown (an ambiguous lottery). In both sets of decisions, a risk neutral participant should choose to draw a ball from the urn until the certain payoff is equal to at least $€ 2.5$. In the first set, a risk averse participant should switch from the lottery to the certain payoff for certain payoffs lower than $€ 2.5$ and a risk seeking participant should switch for certain payoffs higher than $€ 2.5$. An ambiguity averse (seeking) participant should switch from the lottery to the certain payoff for lower (higher) certain amounts in the second set of decisions (the ambiguous lottery) than in the first set (the risky lottery). Decisions are made at the beginning of the session and participants are told that the outcome of these decisions will be determined only at the very end of the session once all other experimental tasks have been completed. When making their decisions, participants are also informed that one of the two sets of decisions will be randomly drawn for real payoffs at the end of the session. 
In all treatments, when participants decide not to start a new period or when the final period has been reached, they have to answer questions as to why they did or did not decide to exit. A demographic questionnaire follows.

\subsection{A Bayesian model of reinforcement}

Given that participants do not know the probabilities that periods will or will not be paid, nor that this probability can change at any time, one should ask what is appropriate for them to reason a priori. One obvious rational candidate is a Bayesian model in which participants update their estimates of the probability that a particular period will be paid given the past history of payments experienced up to that point. ${ }^{7}$ However, this model requires different assumptions that may or may not be appropriate.

In Appendix B, we present implications of different Bayesian models for the baseline and fixed intermittent reinforcement treatment, respectively. Taking all data into account, these models predict that participants should continue in the sessions through period 35 even though the probability of payment starts decreasing after period 20 . However, if the Bayesian model is based on limited memory (i.e., only the $k$ last observations), exiting before period 35 is seen to be rational for specific values of $k$.

\subsection{Experimental procedures}

The experiment consisted of 12 sessions conducted at the laboratory of the GATE (Groupe d'Analyse et de Théorie Economique) research institute in Lyon, France. Between 12 and 19 individuals took part in each session, for a total of 210 participants invited via the ORSEE software (Greiner, 2004). No individual participated in more than one session. The

\footnotetext{
7 Of course, if participants knew a priori that no payments would be made after some unspecified period, a Bayesian model could be formulated to calculate the odds of sampling from one process or another (see, e.g., Kacelnik et al., 1987; Massey and Wu, 2005). However, since our participants were not aware that there would be such a change, we are not convinced that this would provide a reasonable normative benchmark.
} 
participants were mostly undergraduate students from the local engineering and business schools. In each treatment, half of the sessions were run at 12 noon and half were run at $2 \mathrm{pm}$, to control for the possibility that exiting decisions could be influenced by differing opportunity costs of time during the day. Table 1 displays summary information about the sessions. It states the session number, number of participants, percentage of male participants per session, and the treatment. ${ }^{8}$

\section{(Insert Table 1 about here)}

Five participants were invited in a session every quarter of an hour. Upon arrival, a participant was directly sent to the laboratory and was randomly assigned to a computer terminal by drawing a tag from a bag. Therefore, when entering the laboratory most participants found others already working at the task. This procedure aimed at making it impossible for anybody to know how much time other participants had been in the laboratory. Indeed, the moment when a participant left the laboratory was not informative as to the period when he or she exited the task.

The participants found the instructions for both the risky and ambiguous lotteries in their cubicle (see Appendix A). They raised a hand if they had questions. Questions were answered in private. Then, after the decisions were completed, the experimenter took back the instructions and decision sheets for the elicitation tasks and distributed the instructions for the main task. Again, questions were answered in private. When ready, participants could start by playing two practice periods on the computer to familiarize themselves with the task. Except for the elicitation of attitudes toward risk and ambiguity that used pen and paper, the experiment was computerized, using the REGATE platform (Zeiliger, 2000).

\footnotetext{
${ }^{8}$ We ran five sessions of the baseline and five sessions of the random intermittent reinforcement treatment but only two sessions of the fixed intermittent reinforcement treatment (with 36 independent observations). This was because we considered the latter to be more of an intermediate treatment. In fact, it turned out that the treatment effects were so strong that we did not deem it necessary to collect more observations.
} 
After completion of the final demographic questionnaire, the participants were informed on their screens that they were allowed to leave the laboratory, they should not speak to anyone and proceed to the payment room. There, each participant was first asked to flip a coin to determine which set of decisions would be played for real. Then, he or she drew a tag from a box to determine which of the 20 decisions would be considered. If for this decision, the participant had chosen the certain payoff at the beginning of the session, this amount was added to his or her other earnings. If the lottery was chosen, the participant drew a ball from either from a transparent bag (the risky lottery) or from a dark bag (the ambiguous lottery). If the ball was yellow, $€ 5$ were added to the other earnings and $€ 0$ otherwise. Then, the participant could leave the building.

The experiment lasted on average 70 minutes, including the payment of participants, and each participant earned an average of $€ 14.29$ (standard deviation $€ 2.81$ ), including a show-up fee of $€ 4$ and the payoff from either the risky or the ambiguous lottery.

\section{RESULTS}

\subsection{Descriptive statistics}

The main questions of interest focus on the performance across trials of the participants in the three treatment groups, specifically: (1) When do they exit the experimental task? (2) How do they perform? (3) How much do they earn?

\subsubsection{Exiting time patterns}

Figure 1 shows when participants in the three treatment groups exit the task (from the end of periods 15 to 35 ). Figure 2 complements this by displaying the percentages of participants in the three treatment groups who had not exited the task after the $15^{\text {th }}, 20^{\text {th }}, 25^{\text {th }}, 30^{\text {th }}$, and $35^{\text {th }}$ 
periods. To interpret these figures, recall that period 15 ends the compulsory stage and that payment is stopped after period 20 .

\section{(Insert Figures 1 and 2 about here)}

Both figures reveal that the distributions of exiting behavior differ across treatments. In the baseline, the distribution is approximately symmetrical with a median (and mode) of $17 \%$ at the $22^{\text {nd }}$ period (see Fig. 1 ). Compared to the intermittent reinforcement treatments, few participants in the baseline treatment exit the task when it continues to be paid but is no longer compulsory. However, the effect of stopping payment is dramatic (see Fig.2). By the end of period 25 , only $29 \%$ of baseline participants remain in the task. At the end of the task (period 35, when participants were required to stop), only $2 \%$ remain.

The distribution of exiting periods is strikingly different in the random intermittent reinforcement (random IR hereafter) treatment. Most importantly, the mode of the distribution corresponds to period 35 in which $20 \%$ of the participants have to be forced to stop (see Fig.1). In addition, 36\% of the participants in the random IR treatment exit between periods 15 and 20, i.e., before payment stops, while the corresponding percentages are $20 \%$ in the baseline and $25 \%$ in the fixed intermittent reinforcement (fixed IR hereafter) treatment. Compared with the other treatments, randomness of reinforcement is associated with a less steep decline in the number of participants remaining over time (see Fig.2).

The pattern of the fixed IR treatment is relatively close to that of the random IR treatment, but there are some differences. The fixed IR treatment has a tri-modal distribution: $11 \%$ of the participants exit at period $15,17 \%$ at period 26 , and $8 \%$ at each of the $33^{\text {rd }}, 34^{\text {th }}$, and $35^{\text {th }}$ periods (see Fig.1). Participants in the fixed IR treatment are somewhat slower to exit the task than those in the random IR treatment before period 25, but after this the rate of exiting increases and only $8 \%$ remain after period 35 (see Fig.2). 
Kolmogorov-Smirnov tests (K-S hereafter) confirm that the distribution of exiting periods is significantly different between the baseline and both the random IR treatment ( $p<0.001$, exact) and the fixed IR treatment $(p<0.001$, exact). However, the distributions of the two intermittent reinforcement treatments are not significantly different $(p=0.222$, exact). Mann-Whitney tests (at the mean values; M-W hereafter) show qualitatively similar results. The average exiting period is lower in the baseline than in both the random $(p=$ $0.052)$ and the fixed IR treatments $(p=0.002)$ with no difference between the two IR treatments $(p=0.693){ }^{9}$

\subsubsection{Performance profiles}

Figure 3 displays the evolution of the participants' number of correct answers per period over time in each treatment. Table 2 summarizes the means and standard deviations of four sets of performance measures and the amounts participants received for their task performance. The first set of measures indicates the number of correct answers by blocks of periods. The second set shows the number of correct answers for periods 1 to 20 conditional on whether the previous period (or the previous two periods) gave rise to payment or not; in periods 22 to 35 , the previous period is always unpaid. This set of measures captures whether participants adjust their effort to any regular pattern in payments; i.e., in the fixed IR treatment do they anticipate that the period that follows two unpaid periods will be paid? The third measure indicates the total number of correct answers per treatment. The fourth measure corresponds to the total number of paying points (i.e., net of entry fees) actually earned by the participants by the end of the session. ${ }^{10}$ To

\footnotetext{
${ }^{9}$ We note that due to the specific distributions of exiting periods across treatments, a simple comparison of mean exiting periods would be quite misleading. The means (standard deviations) for the three treatments (baseline, random IR, fixed IR, respectively) are: 23.18 (4.00), 25.48 (7.17), and 26.44 (6.90).

${ }^{10}$ Figure 3 and measures 1, 2 and 3 have been computed with the data from the last six sessions (two per treatment), with $\mathrm{N}=35$ in the baseline treatment, $\mathrm{N}=35$ in the random IR treatment, and $\mathrm{N}=36$ in the fixed IR
} 
make comparisons with the baseline treatment, we have divided this number of paying points by 3 in the two IR treatments.

\section{(Insert Figure 3 and Table 2 about here)}

Both Figure 3 and measures 1 in Table 2 indicate that there is hardly any difference in performance per period between treatments in the first 20 periods. K-S tests confirm that there is no significant difference in the distribution of the number of correct answers in the first 20 periods between the baseline and the random IR treatments $(p=0.492)$, between the baseline and the fixed IR treatment $(p=0.532)$, and between the two IR treatments $(p=$ 0.611). In contrast, once payment stops definitively the average performance in the baseline treatment decreases rapidly whereas effort remains high in both IR treatments. K-S tests show that the distribution of the number of correct answers after period 20 is significantly different between the baseline and the random IR treatment $(p<0.001)$, between the baseline and the fixed IR treatment $(p=0.001)$, but not between the two IR treatments $(p=0.995) .{ }^{11}$ This suggests that participants who do not exit early in the baseline treatment have little motivation but stay just in case payment might restart. In the IR treatments, performance increases slightly throughout the game, due possibly to a combination of learning and selfselection by the most able participants over time.

Figure 3 also indicates that performance fluctuates across periods in each treatment but no regular pattern emerges. In particular, measures 2 in Table 2 show that in the fixed IR

treatment. Measure 4 has been computed with the data from the 12 sessions $(\mathrm{N}=89$ in the baseline treatment, $\mathrm{N}=85$ in the random IR treatment, and $\mathrm{N}=36$ in the fixed IR treatment). The reason is that, by mistake, the number of correct answers was recorded only in the paid periods in the first six sessions (three with the baseline and three with the random IR treatments). Therefore, we do not use these sessions for the calculation of the first four measures. Figure 3 is also based on the data of the last six sessions. We note, however, that the distribution of exiting periods by treatment is the same in the first six and the last six sessions (K-S test, $p=0.398$ for the baseline and $p=0.937$ for the random IR treatment).

${ }^{11} \mathrm{M}-\mathrm{W}$ tests on the number of correct answers by blocks of periods reach the same conclusions. For periods 1 to 20 , the $p$-value is 0.819 for the comparison between the baseline and the random IR treatment, 0.617 for the comparison between the baseline and the fixed IR treatment, and 0.774 for the comparison between the two IR treatments. For periods 21 to 25 , the p-values are $0.084,0.290$ and 0.418 , respectively. For periods 26 to 30 , they are $0.016,0.009$, and 0.966 . Last, for periods 31 to 35 , they are $0.031,0.097$, and 0.550 . 
treatment participants do not learn that in the first 20 periods a period is always paid after two unpaid periods. Indeed, in this treatment performance in the first 20 periods is not higher after two periods unpaid than after one unpaid period (Wilcoxon test, $p=0.642$; for the random IR treatment, $p=0.646$ ). Similarly, performance does not decline after one period has been paid (Wilcoxon test, $p=0.712$ ). ${ }^{12}$ Fluctuations between two periods are more likely due to variations in task difficulty (i.e., the number of occurrences of a letter).

Last, measures 3 in Table 2 indicate that the total performance is lower in the baseline $($ mean $=66.91$ correct answers $)$ than in the random $($ mean $=80.83, \mathrm{M}-\mathrm{W}$ test: $p=$ 0.069 ) and the fixed IR treatments (mean $=84.28, p=0.003$ ), with no difference between the last two treatments $(p=0.709)$. This results from longer participation in the IR treatments.

\subsubsection{Average payoffs}

Consider now the net amount of paying points earned by the participants in the 12 sessions. Measures 4 in Table 2 show that the participants who are still involved in period 20 accumulated more points in the first 20 periods in the random IR treatment $($ mean $=47.37)$ than in the baseline (mean $=42.01 ; \mathrm{M}-\mathrm{W}$ test, $p=0.001)$ and than in the fixed IR treatment (mean $=41.89 ; p=0.028$ ). There is no difference between the baseline and the fixed IR treatments $(p=0.955)$. This higher number of points earned in the random IR treatment could be due to the early exiting of less able participants. If one considers instead the final number of paying points earned by all the participants, we find that this number is slightly higher in the baseline $($ mean $=37.31)$ than in both the random (mean $=35.65 ; \mathrm{M}-\mathrm{W}$ test, $p=$ 0.113 ) and the fixed IR treatments (mean $=33.39 ; p=0.051$ ). There is no difference between the two IR treatments $(p=0.319)$. These differences between points earned until

\footnotetext{
${ }^{12}$ This is confirmed by a visual inspection of the data. Only two subjects learn to reduce their effort after a period has been paid; however, they leave only in periods 29 and 30 .
} 
period 20 and points earned throughout the sessions across treatments are clearly due to the fact that participants entered in more unpaid periods in the IR treatments than in the baseline. Figure 4 displays the distribution of monetary payoffs by treatment.

\section{(Insert Figure 4 about here)}

Figure 4 shows that the baseline treatment leads to higher payoffs than the intermittent reinforcement treatments, while the fixed IR treatment is associated with lower payoffs. Participants in the baseline treatment clearly adapted better to changing circumstances than those in the IR conditions. This is even more notable if one considers that the cost of effort (not monetary in our case) is higher in the IR treatments because people stay longer.

Could these differences between treatments in exiting period, performance, and payoffs be attributed to differences in individual characteristics of the participants in each treatment? To address this question we investigated possible differences between the three treatments in terms of skill at the task as measured by the distribution and the means of correct answers in the two practice rounds as well as the first 15 compulsory periods. None of these differences were significant, although the average score during the practice period was marginally higher in the random IR than the baseline treatment $(p=0.079) .{ }^{13} \mathrm{We}$ found no significant differences in switch point in the ambiguous lottery nor any ambiguity aversion defined as the difference between switch points of the risky and ambiguous lotteries. ${ }^{14}$ Observed differences in exiting periods and effort can thus be imputed to the

\footnotetext{
13 In the following, the three $p$-values correspond always to the comparison between the baseline and the random IR treatment, then between the baseline and the fixed IR treatment, and last between the random and the fixed IR treatments. Regarding the score in practice periods, K-S tests indicate $p=0.270,0.269$, and 0.800 , while M-W tests yield $p=0.079,0.213$, and 0.784 . Regarding the cumulated score at the end of period $15, \mathrm{~K}-\mathrm{S}$ tests indicate $p=1.000,0.975$, and 0.818 , while $\mathrm{M}-\mathrm{W}$ tests yield $p=0.934,0.904$, and 0.977 . Last, considering the cumulated number of mistakes during the 15 periods of the compulsory task, K-S tests indicate $p=0.999$, 0.785 , and 0.594 , while $\mathrm{M}-\mathrm{W}$ tests yield $p=0.724,0.890$, and 0.738 .

${ }^{14}$ With the same convention as in the previous footnote, K-S tests yield $\mathrm{p}=0.923,0.871$, and 0.863 for the switching point for the ambiguous lottery, and $\mathrm{p}=0.710,0.998$, and 0.548 for ambiguity aversion.
} 
treatment manipulation and not to different characteristics of the participants across treatments.

\subsection{Econometric analyses}

To complement this analysis we carried out some econometric tests. First, we estimated a tobit model in which the dependent variable is the period at the end of which the participant decided to exit the session. The tobit model is used because data are censored both on the left (participants are not allowed to exit before the end of period 15) and on the right (they cannot start a $36^{\text {th }}$ period). The independent variables include dummy variables for the random IR treatment and the fixed IR treatment, with the baseline as the reference category. They also include a dummy variable for the afternoon sessions since participants may have a higher opportunity cost for staying longer in the afternoon than during the lunch break. The rank of arrival variable aims at capturing the impact on the participant's exiting decision of observing other participants leaving. Participants who arrive late might decide to exit earlier simply because they see their peers leaving the laboratory before them. ${ }^{15}$

The other variables capture individual characteristics. The skill variable takes the value of the number of correct answers provided in the 15 compulsory periods. ${ }^{16} \mathrm{We}$ hypothesize that participants who are less able at the task may leave earlier than the more able. We include three variables for capturing the attitudes of participants towards risk and ambiguity. The risk index indicates the number of the decision where the participant switched from the lottery to the certain equivalent. The higher (lower) the value of the variable, the less (more) risk averse the participant, since this indicates valuing the lottery

\footnotetext{
${ }^{15}$ The rank of arrival is a better instrument to capture peer effects in exiting than the rank of departure because the former is exogenous while the latter is endogenous to the exiting decision.

16 We consider the first 15 periods since all the participants play the same number of periods. Lacking systematic records of all performance for the first six sessions of the baseline and random IR treatments, we calculated the average performance per paid period in the first 15 periods and multiplied this number by 15 .
} 
more (less). The ambiguity aversion variable expresses the difference between the value of the switching point in the risky lottery and the value of the switching point in the ambiguous lottery. This variable can take positive or negative values. A positive (negative) value means that the participant has switched from the random drawing to the certain equivalent earlier (later) for the ambiguous lottery than for the risky lottery, thereby indicating some ambiguity aversion. Since 22 out of 210 participants $(10.5 \%)$ switched several times, a dummy variable captures this inconsistency to control whether it influences behavior. ${ }^{17}$

We further ask the participants to report their belief about family wealth relative to their schoolmates on a scale from 1 (among the $10 \%$ least wealthy families) to 10 (among the $10 \%$ wealthiest families). This aims at measuring participants' resources since less wealthy students may stay longer in the hope of making more money during the experiment. We include other controls for age, gender, and number of years of post secondary school education. We also control for level of excellence on high school certificates (from 1 for "no distinction" to 4 for "very good") since it provides a measure of cognitive abilities. The results of this regression are displayed in the second column of Table 3 (model (1)).

\section{(Insert Table 3 about here)}

The estimation of model (1) in Table 3 indicates that the participants work significantly longer when rewards in the first 20 periods are intermittent as opposed to continuous. The coefficients of the two treatment variables are significant at the $1 \%$ level and positive relative to the baseline. The moment of the day when the experiment was run exerts no significant effect. Nor do we find evidence of peer effects on the exiting decision as the coefficient of the rank of arrival is negative but not significant. In contrast, the exiting decision is influenced by the participants' skill at the task (significant at the $5 \%$ level). The more able participants stay longer, probably because providing more correct

\footnotetext{
${ }^{17}$ In case of multiple switches, we determine risk attitude with the average value of the switching decisions.
} 
answers is in itself a form of reinforcement as well as providing a higher reference point for performance. Also, more risk-seeking participants enter more periods (significant at the 5\% level), while risk averse people are less willing to pay to enter additional periods with uncertain benefits.

This tobit model is not sufficient, however, for explaining behavior because the distributions of times of exiting decisions differed significantly across treatments. In particular, some participants exited the game between the $16^{\text {th }}$ and the $20^{\text {th }}$ period, i.e., before we stopped payment. This could indicate the presence of a selection bias in the estimation. Therefore, we study the determinants of the exiting decision after we definitively stopped assigning paying points, conditional on the participants working until the end of the $20^{\text {th }}$ period. To do so, we estimate a two-step Heckman model with sample selection. We first estimate the determinants of the decision to work until the end of the $20^{\text {th }}$ period by means of a probit model. The independent variables are the same as in the previous tobit model. Then, we estimate the determinants of the exiting period for those participants who stay at least 20 periods by means of an OLS model in which we include the Inverse of the Mills' Ratio (IMR) obtained from the estimation of the first equation to control for the potential sample selection bias. To identify the model, we drop from the second equation the skill variable that turns out to have a significant influence on the decision to work at least 20 periods. The outcomes of these regressions, together with the marginal effects of the variables in the probit model, are displayed in the last two columns of Table 3.

The estimation of model (2) indicates that the participants in the random IR treatment are significantly more likely (at the $1 \%$ level) to exit the game prematurely before we stop rewarding effort than those in the baseline. The random IR treatment increases this probability by $19 \%$. In contrast, there is no difference between the fixed IR and the baseline 
treatments. It is randomness rather than the frequency of rewards that influences decisionmaking. One interpretation is that randomness of rewards depresses intrinsic motivation. Another is that randomness makes signals (i.e., the payment of a period) less informative concerning expectations for the ensuing periods.

We also find that participating in an afternoon session decreases the probability of staying at least 20 periods by $13 \%$ (significant at the $5 \%$ level), which can possibly be explained by a higher opportunity cost of participating in the afternoon than during the lunch break. We also find that the probability of staying at least 20 periods is increased by the participants' skills and a lower degree of risk aversion (both significant at the $5 \%$ level). The less able participants may think that their cost of effort is too high to be compensated by this type of payment scheme and are more likely to exit as early as possible. Controlling for risk attitude, ambiguity aversion has a positive effect on the decision to stay at least 20 periods. One interpretation is that ambiguity averse participants are willing to stay longer, ceteris paribus, if they expect that this will help them become better informed about the returns on their efforts. Last, participants who report belonging to wealthier families than their schoolmates are more prone to early exiting, perhaps because they value less the payoff they can obtain from continuing in the experiment. Believing that one belongs to a wealthier family decreases the probability of still participating in the $20^{\text {th }}$ period by $3 \%$ per decile.

Conditional on participating for at least the first 20 periods, the estimation of model (3) indicates that both IR treatments affect the total duration of work during the unpaid interval. The coefficients of both variables are highly significant (at the $1 \%$ level) and the coefficient of the random IR treatment is larger than that of the fixed IR treatment. On average, a participant in the random IR treatment works 6.6 periods longer than a participant in the baseline, the comparable figure for the fixed IR treatment being 5.6. The older 
participants work significantly longer (at the 1\% level) than the younger ones and those with more years of study exit earlier (significant at the $10 \%$ level). None of the other variables has a significant impact. In particular, attitudes towards risk or ambiguity have no additional effects once we control for their impact on work until the $20^{\text {th }}$ period. The coefficient of the IMR variable is not significant, showing that there is no selection bias.

To complete this analysis, we have also estimated the determinants of the probability of working until the limit of the $35^{\text {th }}$ period. These estimates are displayed in Table 4 . Model (1) corresponds to the second equation of a two-step probit model with sample selection, in which the selection equation is the probability of working at least 20 periods (as in model (2) reported in Table 3). It estimates the probability of reaching the $35^{\text {th }}$ period conditional on working at least 20. Since the estimations reported in Table 3 showed that there is no selection bias in the probability of working at least 20 periods, we have also estimated an unconditional probit model (model (2)). The independent variables are the same as in the regressions reported in Table 3 except that we also include the participant's skill in model (2). In addition, marginal effects of the variables in the second model are displayed.

\section{(Insert Table 4 about here)}

Both models reach the same conclusions. While the probability of working until the end of the $35^{\text {th }}$ period increases marginally for the fixed IR treatment (significant at the $10 \%$ level), the effect is highly significant (at the $1 \%$ level) for the random IR treatment. In model (2), the marginal effects of these treatments are $13 \%$ and $21 \%$, respectively. Controlling for number of years of study, we find that one year of age increases the probability of reaching the limit by $2 \%$. These regressions confirm that the main forces driving behavior in this task are, first, the randomness of rewards and, second, their frequency. 


\subsection{Reasons to continuelexit the session}

As noted above, we also asked participants their motives for exiting when they did or alternatively why they continued through period 35 . The 17 participants in the random IR treatment who stayed until the end cited a total of 26 "first" reasons for continuing. Ten of these participants $(59 \%)$ reported that they hoped "to earn more" and another three $(18 \%)$ said that they had not reached their "target income for the day." "Like task" was cited first by three participants. The remaining 10 responses were quite varied including the willingness not to stop before others, maximizing the numbers of correct answers, and even difficulties associated with stopping. ${ }^{18}$ Table 5 presents a classification of the most important reasons cited for exiting the task before the $35^{\text {th }}$ period broken down by experimental treatments. The last column of Table 5 reports the estimates of an ordinary least square model in which the dependent variable is the number of the exiting period. The independent variables include dummies for each IR treatment and each of the possible reasons cited by the participants when exiting voluntarily, either in first, second or third position.

\section{(Insert Table 5 about here)}

Table 5 shows that financial reasons (monetary tradeoffs and income targeting) dominate in all treatments. Approximately three-fourths of all answers cite these reasons. Aspects related to the game itself are only cited first some $20 \%$ of the time (across all treatments). The OLS regression indicates that task-related concerns (“don't like task") are associated with earlier exit while monetary reasons ("no more payment") are associated with later exit.

\footnotetext{
${ }^{18} \mathrm{We}$ do not comment on responses at the 35 th period of participants in the fixed IR and baseline treatments because there were only 3 and 2 participants, respectively.
} 


\section{DISCUSSION AND CONCLUSION}

To summarize, when individuals have to set goals for themselves, we note strong effects of both frequency and regularity in the different compensation schemes (i.e., reinforcement schedules). Participants who are used to being paid in every period react quickly to the extinction of payment by exiting. Participants who are paid infrequently react differently if their payments are or are not regular. Irregular (or randomly timed) payment induces greater persistence in the task. One further fact should be added. While participants in the IR conditions exerted far more effort than their baseline counterparts - especially after payment stopped -on average, they earned less.

A Bayesian model that uses all the data and assumes a stationary probabilistic process cannot predict the observed behavior. On the other hand, a Bayesian model with imperfect memory (i.e., limited to the last $k$ observations) is more successful at capturing the general patterns we observed because of its sensitivity to more recent observations. Some form of limited memory model is broadly consistent with our findings of earlier exit in the baseline as opposed to fixed IR groups. For the participants, the short memory models are functional because they allow adaptation to changes in the underlying probability of payment. But these models are not sufficient to explain the observed behavior, notably the coexistence of premature exiting and long persistence in the random IR treatment. The work of Koszegi and Rabin (2006), where a person's reference point is her rational expectation based on past outcomes, can help in interpreting our results. Indeed, our results could indicate that while individuals set reference points in earnings expectations for themselves, both the degree of continuity and randomness of the reinforcement schedule influence the updating of this reference point over time. Evaluations of changes in earnings expectations may be influenced by the reinforcement schedule in use, which contributes to determine the exiting decision. In particular, if payment of a period is interpreted as a signal 
to update earnings expectations, the randomness of rewards decreases the value of this signal and people have more trouble learning from reward prediction errors. This may lead some people to exit prematurely because the signal has no informative value and, on the contrary, for others to persist and collect information by observing more signals across time.

We now consider our results from three perspectives: unique features of our experimental set-up; the rationality or otherwise of persistent behavior; and implications of different reinforcement schedules for economic activity.

The fact that our results are consistent with experiments conducted on persistence and escalation under different conditions (see, e.g., Golz, 1992; Brecher \& Hantula, 2005) ${ }^{19}$ speaks, in our view, to the strength of the reinforcement manipulation in our experiment and rules out the need to postulate social explanations such as self-justification (Brockner, 1992). Note, however, that we are not arguing that processes such as self-justification do not occur when persistence is observed in naturally occurring environments. What we have shown is that differential persistence can occur as a result of various reinforcement schedules, i.e., in the absence of motives such as self-justification.

Does the persistence observed in our experiment represent rational behavior? With the benefit of hindsight, one can argue that baseline participants were more "rational" than their IR counterparts because they earned more money. O'Flaherty and Komaki (1992) show that some persistence in behavior can be explained using a Bayesian updating model. The key idea is that the learning parameters differ depending on whether feedback has been continuous or intermittent (there is less uncertainty associated with the former). Massey and $\mathrm{Wu}$ (2005) explicitly modeled situations where, as in our experiment, agents experience

\footnotetext{
${ }^{19}$ First, instead of answering hypothetical questions and being compensated at the same rate as other participants (e.g., by satisfying a course participation requirement), all actions by our participants involved specific monetary incentives. Second, our participants were not asked to adopt a role in answering questions. They made decisions for themselves. Third, our task required physical effort in the form of counting letters in words. It did not involve reacting to an investment-type decision. Moreover, it was clear that there was a connection between attention paid to the task and monetary rewards.
} 
regime shifts. In their experiment, participants observe signals and must indicate if and when they believe there has been a shift from one regime to another. They find - consistent with a "system neglect" hypothesis - that people underreact in unstable environments with precise signals but that they overreact in stable environments with noisy signals. Interestingly, in our experiment, signals were quite precise (people were or were not paid), but it is an open question as to whether one would consider the environment stable or not. In short, and also taking into account the views expressed by Dixit (1992), it is difficult to state that persistent behavior, triggered by intermittent reinforcement schedules, is or is not economically rational ex ante. The learning processes used by humans and other animals are often based on observing sequential signals and they are typically both automatic and highly adaptive. As such, we would expect that they are rational a priori. However, this does not exclude the possibility that they could lead to serious errors on occasion.

Data concerning economic phenomena are experienced largely across time. Consider stock market prices, interest rates, prices of commodities, payments by customers, and so on. Often these data are interpreted as signals about the underlying state of an economic system (e.g., the stock market or a customer's financial situation) and are used to update opinions through a process of learning. We emphasize three characteristics of these situations. First, the systems can be unstable in the sense that underlying probabilities change across time, e.g., a bear market becomes a bull market. Second, informational feedback - or reinforcement - can vary from continuous to variable intermittent. Consider, for example, the difference between stable and turbulent market conditions. And third, people typically experience reinforcement schedules passively, i.e. they must just accept the data as they are generated by the market. Thus, the fact that after experiencing different reinforcement schedules human learning processes should naturally lead to different 
reactions (e.g., quit or persist) is important. Overall, it is surprising that these distinctions in what effects learning have failed to attract more attention from economists.

We started this paper with a finding of excess trading in the stock market and the remark that this could not just be explained by overconfidence. There had to be some additional explanation. Clearly, we don't know whether the excess trading observed by Odean (1999) was due to reactions by traders to random intermittent reinforcement. However, given our experimental findings, it does seem a good hypothesis to pursue as does the general issue of the differential effects of various reinforcement schedules on economic behavior. 


\section{REFERENCES}

Balleine, B.W., Daw, N.D., \& O’Doherty, J.P. (2009). In Glimcher, P.W., Camerer, C.F., Fehr, E., \& Poldrack, R.A. (Eds.), Neuroeconomics, Decision-Making and the Brain. Amsterdam: Elsevier, 367-387.

Bowen, M. G. (1987). The escalation phenomenon reconsidered: Decision dilemmas or decision errors? Academy of Management Review, 12 (1), 52-66.

Bretcher, E. G., \& Hantula, D. A. (2005). Equivocality and escalation: A replication and preliminary examination of frustration. Journal of Applied Social Psychology, 35, (12), 2606-2619.

Brockner, J. (1992). The escalation of commitment to a failing course of action: Toward theoretical progress. Academy of Management Review, 17 (1), 39-61.

Camerer, C.F., Babcock, L., Loewenstein, G., \& Thaler, R. (1997). Labor Supply of NewYork City Cabdrivers: One Day at a Time. Quarterly Journal of Economics, 112(2), 407-441.

Camerer, C. F., \& Hogarth, R. M. (1999). The effects of financial incentives in experiments: A review and capital-labor-production framework. Journal of Risk and Uncertainty, $19,7-42$.

DeNicolis Bragger, J., Bragger, D., Hantula, D. A., \& Kirnan, J. (1998). Hysteresis and uncertainty: The effect of uncertainty on delays to exit decisions. Organizational Behavioral and Human Decision Processes, 74 (3), 229-253.

DeNicolis Bragger, J., Hantula, D. A., Bragger, D., Kirnan, J., \& Kutcher, E. (2003). When success breeds failure: History, hysteresis, and delayed exit decisions. Journal of Applied Psychology, 88 (1), 6-14.

Deslauriers, B. C., \& Everett, P. B. (1977). Effects of intermittent and continuous token reinforcement on bus ridership. Journal of Applied Psychology, 62 (4), 369-375.

Dixit, A. (1992). Investment and hysteresis. Journal of Economic Perspectives, 6 (1), $107-$ 132.

Erev, I., Ingram, P., Raz, O., \& Shany, D. (2010). Continuous Punishment and the Potential of Gentle Rule Enforcement. Behavioural Processes, 84, 366-371.

Eriksson, T., Poulsen, A., \& Villeval, M.C. (2009). Feedback and Incentives: Experimental Evidence. Labour Economics, 16 (6), 679-688.

Fehr, E., \& Goette, L. (2007). Do Workers Work More if Wages Are High? Evidence from a Randomized Field Experiment. American Economic Review, 97(1), 298-317.

Ferster, C. S., \& Skinner, B. F. (1957). Schedules of Reinforcement, New York, NY: Appleton-Century-Crofts.

Fox, C.R., \& Tversky, A. (1995). Ambiguity Aversion and Comparative Ignorance. The Quarterly Journal of Economics, 110(3), 585-603.

Goette, L., Huffman, D., \& Fehr, E. (2004). Loss Aversion and Labor Supply. Journal of the European Association, 2(2-3), 216-228.

Goette, L., \& Huffman, D. (2006). Incentives and the Allocation of Effort over Time: The Joint Role of Affective and Cognitive Decision Making. IZA Discussion Paper 2400, Bonn.

Golz, S. M. (1992). A sequential learning analysis of decisions in organization to escalate investments despite continuing costs or losses. Journal of Applied Behavior Analysis, 25, 561-574.

Greiner, B. (2004). “An online recruitment system for economic experiments." In Forschung und wissenschaftliches Rechnen GWDG Bericht 63, Ed. K. Kremer, and V. Macho. Göttingen: Gesellschaft für Wissenschaftliche Datenverarbeitung. 
Hantula, D. A., \& Crowell, C. R. (1994). Intermittent reinforcement and escalation processes in sequential decision making: A replication and theoretical analysis. Journal of Organizational Behavior Management, 14 (2), 7-36.

Hantula, D. A., \& DeNicolis Bragger, J. L. (1999). The effects of feedback equivocality on escalation of commitment: An empirical investigation of decision dilemma theory. Journal of Applied Social Psychology, 29 (2), 424-444.

Hilgard, E. R., \& Bower, G. H. (1975). Theories of Learning, $4^{\text {th }}$ ed, Englewood Cliffs, NJ: Prentice-Hall.

Kacelnik, A., Krebs, J. R., \& Ens, B. (1987). Foraging in a changing environment: An experiment with starlings (sturnus vulgaris). In M. L. Commons, A. Kacelnik, \& S, J, Shettleworth (Eds.), Quantitative Analyses of Behavior: Foraging Vol. VI (pp. 6387). Hillsdale, NJ: Lawrence Erlbaum Associates.

Koszegi, B., \& Rabin, M. (2006). A Model of Reference-Dependent Preferences. Quarterly Journal of Economics, 121(4), 1133-1165.

Lazear, E. P. (1990). The timing of raises and other payments. Carnegie-Rochester Conference Series on Public Policy, 33, 13-48.

Lazear, E. P. (1991). Labor economics and the psychology of organizations. Journal of Economic Perspectives, 5 (2), 89-110.

Lerman, D.C., Iwata, B.A., Shore, B.A., \& Kahng, S.W. (1996). Responding Maintained by Intermittent Reinforcement: Implications for the Use of Extinction with Problem Behavior in Clinical Settings. Journal of Applied Behavior Analysis,29, 153-171.

Locke, E.A., \& Latham, G.P. (1990). A theory of goal-setting and task performance. Englewood Cliffs, N.J.: Prentice-Hall.

Massey, C., \& Wu., G. (2005). Detecting regime shifts: The causes of under- and overreaction. Management Science, 51 (6), 932-947.

Montague, P.R., Dayan, P., \& Sejnowski, T.J. (1996). A framework for mesencephalic dopamine systems based on predictive Hebbian learning. Journal of Neurosciences, 16, 1936-1947.

Niv, Y., \& Montague, P.R. (2009). Theoretical and Empirical Studies of Learning. In Glimcher, P.W., Camerer, C.F., Fehr, E., \& Poldrack, R.A. (Eds.), Neuroeconomics, Decision-Making and the Brain. Amsterdam: Elsevier, 367-387.

Odean, T. (1999). Do investors trade too much? American Economic Review, 89 (5), 12791298.

O'Flaherty, B., \& Komaki, J. L. (1992). Going beyond with Bayesian updating. Journal of Applied Behavior Analysis, 25, 585-597.

Schultz, W., Apicella, P., \& Ljungberg, T. (1993). Responses of monkey dopamine neurons to reward and conditioned stimuli during successive steps of learning a delayed response task. Journal of Neurosciences, 13, 900-913.

Sutton, R.S., \& Barto, A.G. (1998). Reinforcement Learning. Cambridge, MA: MIT Press.

Staw, B.M. (1976). Knee-deep in the big muddy: A study of escalating commitment to a chosen course of action. Organizational Behavior and Human Performance, 16, $27-$ 44.

Staw, B.M., \& Ross, J. (1989). Understanding behavior in escalation situations. Science, 246, 216-220.

Zeiliger, Romain, (2000). A Presentation of Regate, Internet Based Software for Experimental Economics. http://www.gate.cnrs.fr/ zeiliger/regate/RegateIntro.ppt., GATE. 
TABLES AND FIGURES

Table 1. Characteristics of the experimental sessions

\begin{tabular}{cccl}
\hline $\begin{array}{c}\text { Session } \\
\text { number }\end{array}$ & $\begin{array}{c}\text { Number of } \\
\text { participants }\end{array}$ & $\begin{array}{c}\text { Percentag } \\
\text { e of males }\end{array}$ & Treatment \\
\hline 1 & 12 & 42 & Random IR \\
2 & 19 & 47 & Random IR \\
3 & 17 & 29 & Baseline \\
4 & 19 & 42 & Random IR \\
5 & 18 & 78 & Baseline \\
6 & 19 & 32 & Baseline \\
7 & 17 & 59 & Random IR \\
8 & 18 & 39 & Random IR \\
9 & 17 & 47 & Baseline \\
10 & 18 & 72 & Baseline \\
11 & 18 & 50 & Fixed IR \\
12 & 18 & 22 & Fixed IR \\
\hline
\end{tabular}


Table 2. Summary statistics of task performance (in points)

\begin{tabular}{lccc}
\hline Treatments & Baseline & Random IR & Fixed IR \\
\hline 1) Mean performance per period by blocks of periods & & \\
Periods 1-15 (compulsory) & $3.00(1.00)$ & $3.13(0.88)$ & $3.06(0.94)$ \\
Periods 16-20 & $3.16(1.05)$ & $3.33(0.82)$ & $3.26(0.83)$ \\
Periods 21-25 & $3.01(1.03)$ & $3.51(0.61)$ & $3.38(0.85)$ \\
Periods 26-30 & $2.55(1.00)$ & $3.43(0.72)$ & $3.43(0.76)$ \\
Periods 31-35 & $2.17(0.98)$ & $3.42(0.69)$ & $3.38(0.87)$ \\
\hline 2) Mean performance per period & & & \\
Periods 1-20 & $3.04(1.02)$ & $3.27(0.79)$ & $3.10(0.92)$ \\
Previous period paid & - & $3.14(0.90)$ & $3.14(0.91)$ \\
Previous period unpaid & - & $3.17(0.91)$ & $3.12(0.91)$ \\
2 previous periods unpaid & \multicolumn{3}{|l}{} \\
& $2.78(1.06)$ & $3.45(0.67)$ & $3.42(0.79)$ \\
Periods $>$ 21 (previous period unpaid) & $66.91(18.25)$ & $80.83(29.56)$ & $84.28(28.88)$ \\
3) Mean total performance & & & \\
& & & \\
4) Mean total paying points & $42.01(9.81)$ & $47.37(8.33)$ & $41.89(11.49)$ \\
End of period 20 & $37.31(11.47)$ & $35.65(10.78)$ & $33.39(12.57)$ \\
End of sessions & & & \\
\hline
\end{tabular}

Note : Standard deviations are in parentheses. 
Table 3. Determinants of the exiting period

\begin{tabular}{|c|c|c|c|}
\hline \multirow[b]{2}{*}{ Dependent variables } & \multirow{2}{*}{$\begin{array}{l}\text { Tobit model } \\
\text { Exiting period }\end{array}$} & \multicolumn{2}{|c|}{ Heckman two-step model } \\
\hline & & $\begin{array}{l}\text { Probability of still } \\
\text { working in period } \\
20 \\
\text { (2) }\end{array}$ & $\begin{array}{c}\text { Exiting period } \\
\text { conditional on } \\
\text { working in period } \\
20 \\
(3)\end{array}$ \\
\hline $\begin{array}{l}\text { Baseline treatment } \\
\text { Random intermittent reinforcement treatment }\end{array}$ & $\begin{array}{c}\text { Ref. } \\
3.035^{* * *} \\
(1.027)\end{array}$ & $\begin{array}{c}\text { Ref. } \\
-0.597^{* * *} \\
(0.229)\left[-0.191^{* * *}\right]\end{array}$ & $\begin{array}{c}\text { Ref. } \\
6.566^{* * *} \\
(1.013)\end{array}$ \\
\hline Fixed intermittent reinforcement treatment & $\begin{array}{c}4.194 * * * \\
(1.360)\end{array}$ & $\begin{array}{c}-0.006 \\
(0.314)[-0.002]\end{array}$ & $\begin{array}{l}5.585 * * * \\
(0.907)\end{array}$ \\
\hline Afternoon sessions & $\begin{array}{l}-1.476 \\
(0.960)\end{array}$ & $\begin{array}{c}-0.422 * * \\
(0.211)\left[-0.133^{* *}\right]\end{array}$ & $\begin{array}{c}0.302 \\
(0.784)\end{array}$ \\
\hline Rank of arrival & $\begin{array}{l}-0.128 \\
(0.089)\end{array}$ & $\begin{array}{c}-0.005 \\
(0.020)[-0.002]\end{array}$ & $\begin{array}{l}-0.085 \\
(0.060)\end{array}$ \\
\hline Skill & $\begin{array}{r}2.031^{* *} \\
(0.854)\end{array}$ & $\begin{array}{c}0.407 * * \\
(0.183)[0.127]\end{array}$ & - \\
\hline Risk index & $\begin{array}{c}0.417 * * \\
(0.189)\end{array}$ & $\begin{array}{c}0.090^{* *} \\
(0.042)\left[0.028^{* *}\right]\end{array}$ & $\begin{array}{c}0.144 \\
(0.170)\end{array}$ \\
\hline Ambiguity aversion & $\begin{array}{l}0.258 \\
(0.181)\end{array}$ & $\begin{array}{c}0.082^{* *} \\
(0.039)\left[0.026^{* *}\right]\end{array}$ & $\begin{array}{l}-0.040 \\
(0.156)\end{array}$ \\
\hline Multiple switches & $\begin{array}{l}-1.070 \\
(1.586)\end{array}$ & $\begin{array}{c}-0.195 \\
(0.312)[-0.064]\end{array}$ & $\begin{array}{c}-0.420 \\
(1.198)\end{array}$ \\
\hline Relative wealth & $\begin{array}{l}-0.233 \\
(0.222)\end{array}$ & $\begin{array}{c}-0.083^{*} \\
(0.047)\left[-0.026^{*}\right]\end{array}$ & $\begin{array}{c}0.145 \\
(0.188)\end{array}$ \\
\hline Male & $\begin{array}{c}0.155 \\
(0.947)\end{array}$ & $\begin{array}{c}0.214 \\
(0.211)[0.066]\end{array}$ & $\begin{array}{l}-1.145 \\
(0.716)\end{array}$ \\
\hline Age & $\begin{array}{c}0.309 \\
(0.250)\end{array}$ & $\begin{array}{c}-0.028 \\
(0.048)[-0.009]\end{array}$ & $\begin{array}{c}0.496^{* * *} \\
(0.187)\end{array}$ \\
\hline Level at High School final exam & $\begin{array}{l}-0.119 \\
(0.556)\end{array}$ & $\begin{array}{c}-0.045 \\
(0.126)[-0.014]\end{array}$ & $\begin{array}{c}0.015 \\
(0.385)\end{array}$ \\
\hline Number of years of study & $\begin{array}{c}0.345 \\
(0.489)\end{array}$ & $\begin{array}{c}0.131 \\
(0.101)[0.041]\end{array}$ & $\begin{array}{l}-0.660^{*} \\
(0.398)\end{array}$ \\
\hline IMR (Inverse Mill's Ratio) & - & - & $\begin{array}{l}-2.555 \\
(2.722)\end{array}$ \\
\hline Constant & $\begin{array}{l}7.650 \\
(6.702) \\
\end{array}$ & $\begin{array}{l}-0.540) \\
(1.403) \\
\end{array}$ & $\begin{array}{c}16.589^{* * * *} \\
(4.516)\end{array}$ \\
\hline $\mathrm{N}$ & 210 & & \\
\hline Left-censored observations & 12 & & \\
\hline Right-censored observations & 22 & & \\
\hline Wald $\chi^{2}$ & - & & \\
\hline $\operatorname{LR} \chi^{2}$ & 34.71 & & \\
\hline $\begin{array}{l}p>\chi^{2} \\
\text { Log-likelihood }\end{array}$ & $\begin{array}{c}0.001 \\
-618.810\end{array}$ & & \\
\hline
\end{tabular}


Note: Standard errors are in parentheses and marginal effects are in square brackets. $* * *$ means significant at the 0.01 level, ** at the 0.05 level, and * at the 0.10 level. In model (1) data are left censored at period 15 (first period in which subjects are allowed to exit). In model (3), data are censored at period 20. 
Table 4. Determinants of the probability of working until the $35^{\text {th }}$ period (Probit model with sample selection)

\begin{tabular}{|c|c|c|}
\hline $\begin{array}{l}\text { Dependent variable: probability to reach the } \\
35^{\text {th }} \text { period }\end{array}$ & $\begin{array}{l}\text { Probit model with } \\
\text { sample selection } \\
\text { (1) }\end{array}$ & $\begin{array}{l}\text { Unconditional } \\
\text { probit model } \\
(2)\end{array}$ \\
\hline $\begin{array}{l}\text { Baseline treatment } \\
\text { Random intermittent reinforcement treatment }\end{array}$ & $\begin{array}{c}\text { Ref. } \\
1.761^{* * *} \\
(0.417)\end{array}$ & $\begin{array}{c}\text { Ref. } \\
1.403^{* * *} \\
(0.407)\left[0.213^{* * *}\right]\end{array}$ \\
\hline Fixed intermittent reinforcement treatment & $\begin{array}{l}0.835^{*} \\
(0.507)\end{array}$ & $\begin{array}{c}0.837^{*} \\
(0.480)\left[0.127^{*}\right]\end{array}$ \\
\hline Afternoon sessions & $\begin{array}{l}-0.180 \\
(0.372)\end{array}$ & $\begin{array}{c}-0.311 \\
(0.280)[-0.047]\end{array}$ \\
\hline Rank of arrival & $\begin{array}{l}-0.005 \\
(0.027)\end{array}$ & $\begin{array}{c}0.003 \\
(0.026)[0.0005]\end{array}$ \\
\hline Skill & - & $\begin{array}{c}0.077 \\
(0.250)[0.012]\end{array}$ \\
\hline Risk index & $\begin{array}{c}0.006 \\
(0.080)\end{array}$ & $\begin{array}{c}-0.068 \\
(0.276)[-0.010]\end{array}$ \\
\hline Ambiguity aversion & $\begin{array}{c}0.029 \\
(0.074)\end{array}$ & $\begin{array}{c}0.042 \\
(0.056)[0.006]\end{array}$ \\
\hline Multiple switches & $\begin{array}{l}-0.246 \\
(0.520)\end{array}$ & $\begin{array}{c}0.053 \\
(0.051)[0.008]\end{array}$ \\
\hline Relative wealth & $\begin{array}{c}0.078 \\
(0.085)\end{array}$ & $\begin{array}{c}-0.206 \\
(0.457)[-0.031]\end{array}$ \\
\hline Male & $\begin{array}{l}-0.193 \\
(0.306)\end{array}$ & $\begin{array}{c}-0.003 \\
(0.068)[-0.0004]\end{array}$ \\
\hline Age & $\begin{array}{l}0.148^{* *} \\
(0.070)\end{array}$ & $\begin{array}{c}0.127 * * \\
(0.062)[0.019 * *]\end{array}$ \\
\hline Level at High School final exam & $\begin{array}{c}0.160 \\
(0.181)\end{array}$ & $\begin{array}{c}0.153 \\
(0.164)[0.023]\end{array}$ \\
\hline Number of years of study & $\begin{array}{l}-0.224 \\
(0.148)\end{array}$ & $\begin{array}{c}-0.118 \\
(0.127)[-0.018]\end{array}$ \\
\hline Constant & $\begin{array}{c}-4.853 * * \\
(2.404)\end{array}$ & $\begin{array}{c}-5.441 * * * \\
(2.085)\end{array}$ \\
\hline $\mathrm{N}$ & 210 & 210 \\
\hline Left-censored observations & 58 & - \\
\hline Wald $\chi^{2}$ & 23.98 & - \\
\hline $\operatorname{LR} \chi^{2}$ & $\begin{array}{c}- \\
0.021\end{array}$ & $\begin{array}{l}24.56 \\
0.026\end{array}$ \\
\hline $\begin{array}{l}p>\chi^{2} \\
\text { Log-likelihood }\end{array}$ & $\begin{array}{c}0.021 \\
-\end{array}$ & $\begin{array}{c}0.026 \\
-58.158\end{array}$ \\
\hline
\end{tabular}

Note: Standard errors are in parentheses and marginal effects are in square brackets. $* * *$ means significant at the 0.01 level, $* *$ at the 0.05 level, and * at the 0.10 level. 
Table 5. Reasons for exiting before the final period

\begin{tabular}{|c|c|c|c|c|}
\hline & \multicolumn{3}{|c|}{ 1st reason for exiting (in \%) } & \multirow{2}{*}{$\begin{array}{l}\text { Exiting period (OLS } \\
\text { model, pooled data) }\end{array}$} \\
\hline & Baseline & Random IR & Fixed IR & \\
\hline \multicolumn{5}{|l|}{ - Monetary tradeoffs } \\
\hline No more paid & 47 & 44 & 58 & $6.511 * * *(0.815)$ \\
\hline Didn't earn enough & 11 & 13 & 12 & $-0.554(0.742)$ \\
\hline Other appointment & 14 & 16 & 6 & $0.361(0.781)$ \\
\hline Hungry & 3 & 1 & 3 & $1.607(0.985)$ \\
\hline \multicolumn{5}{|l|}{ - Income targeting } \\
\hline Cannot reach target & 6 & 4 & 0 & $-0.315(0.982)$ \\
\hline $\begin{array}{l}\text { Enough money for today } \\
\text { - Task related }\end{array}$ & 5 & 7 & 0 & $0.753(1.010)$ \\
\hline Don`t like & 2 & 10 & 12 & $-2.815 * * *(0.825)$ \\
\hline Boredom & 8 & 4 & 6 & $-1.183(0.804)$ \\
\hline Tiredness & 11 & 7 & 3 & $0.569(0.782)$ \\
\hline Too hard & 2 & 1 & 0 & $-0.404(1.709)$ \\
\hline Others & 6 & 6 & 0 & $-0.794(0.951)$ \\
\hline Random IR treatment & & & & $1.597 * *(0.661)$ \\
\hline Fixed IR treatment & & & & $3.097 * * *(0.838)$ \\
\hline Constant & & & & $18.622 * * *(1.464)$ \\
\hline Number of observations & 87 & 68 & 33 & 188 \\
\hline Adjusted $\mathrm{R}^{2}$ & - & - & - & 0.428 \\
\hline
\end{tabular}

Note: In the first three columns regarding the $1^{\text {st }}$ reason for exiting the sum of percentages is higher than $100 \%$ as participants could give more than one first reason. In the OLS (Ordinary Least Squared) model, data exclude observations from period 35 since in period 35 participants could not decide to exit. Standard errors are in parentheses. *** means significant at the 0.01 level, ** at the 0.05 level, and * at the 0.10 level. 


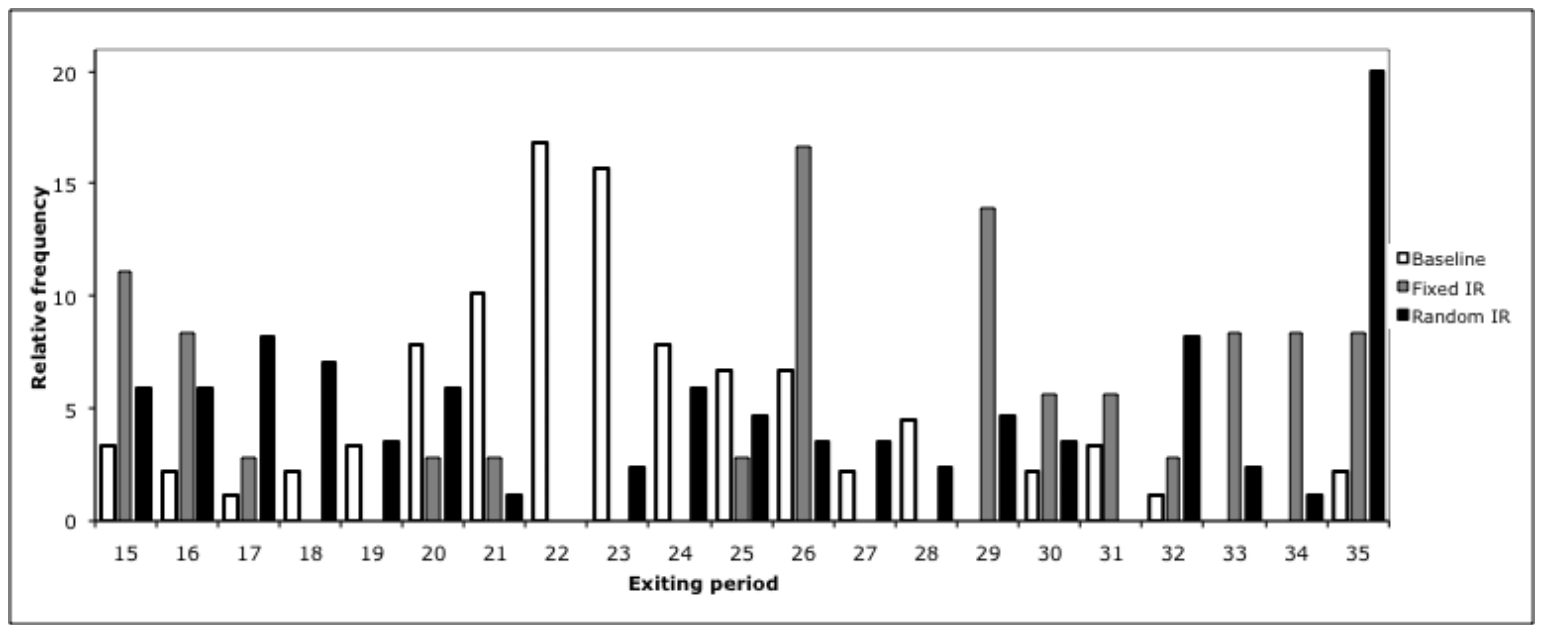

Fig.1. Distribution of the relative frequency of exiting periods by treatment 


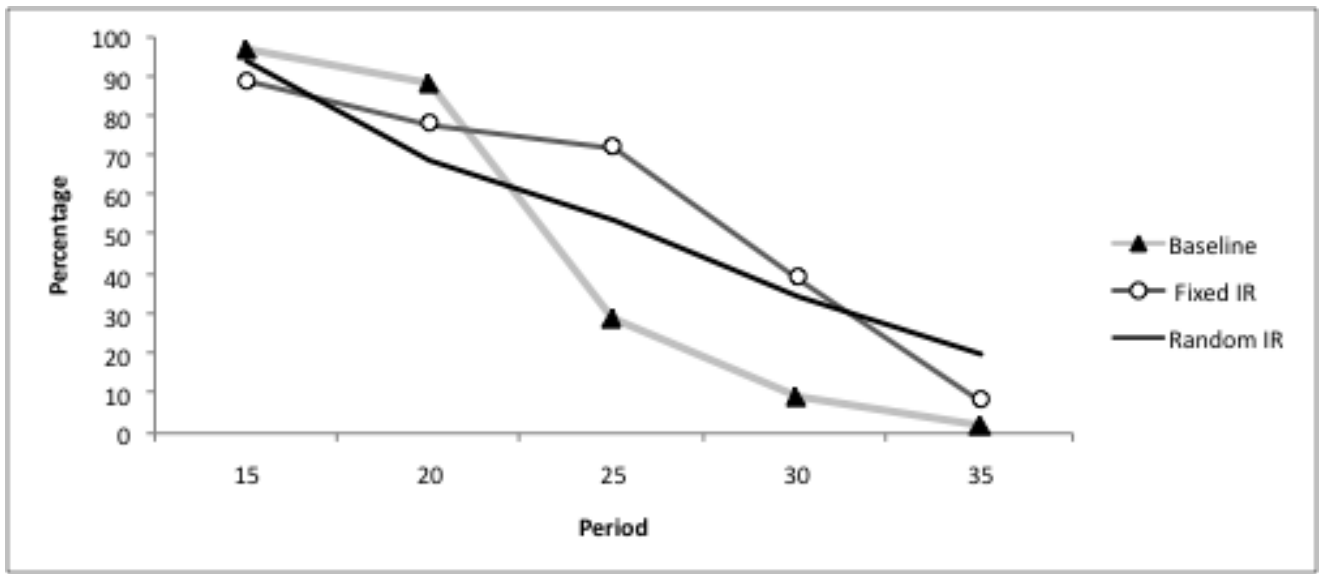

Fig.2. Percentage of participants remaining after the $15^{\text {th }}, 20^{\text {th }}, 25^{\text {th }}, 30^{\text {th }}$, and $35^{\text {th }}$ periods 


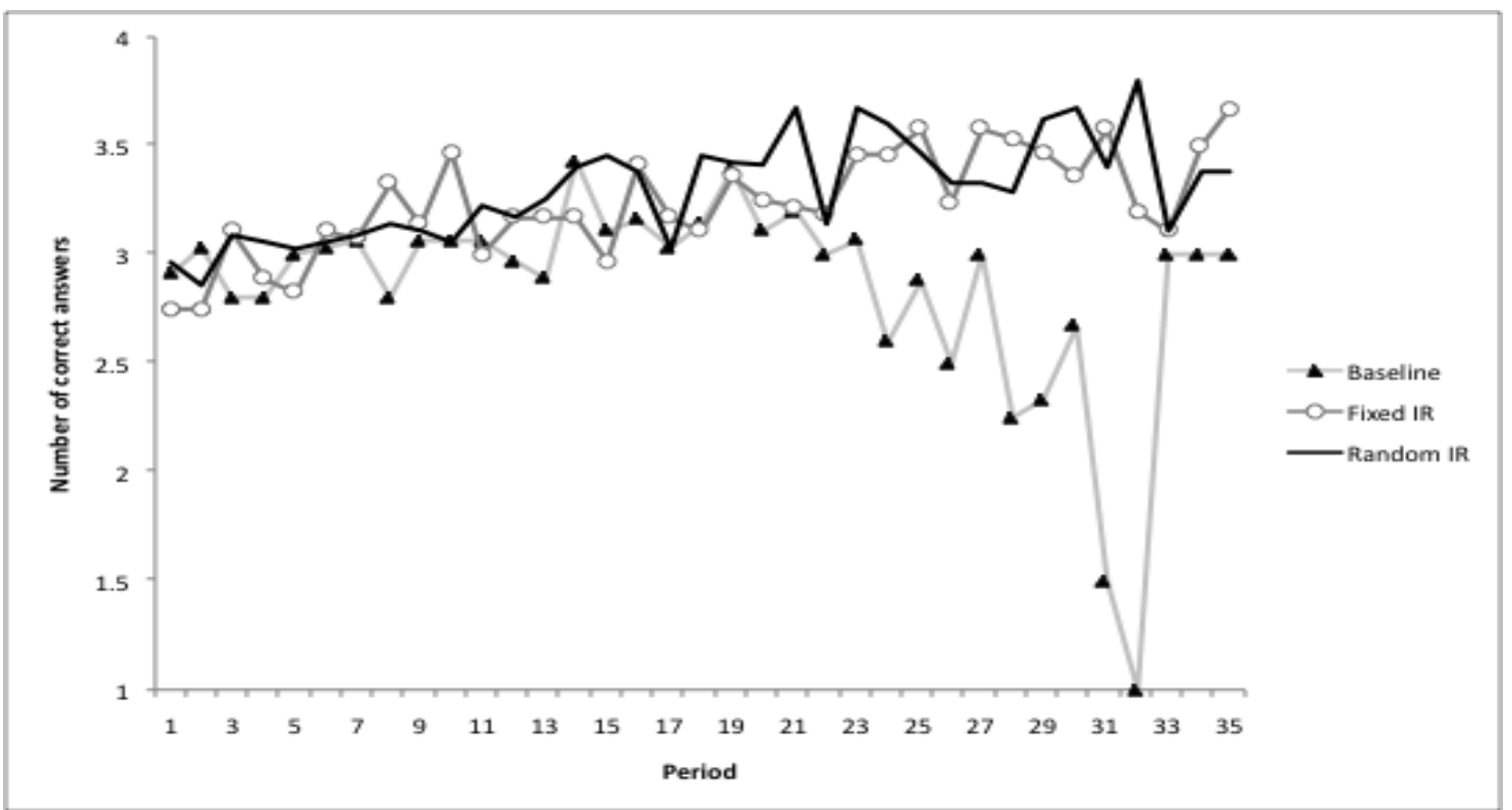

Fig.3. Evolution of the number of correct answers over time by treatment 


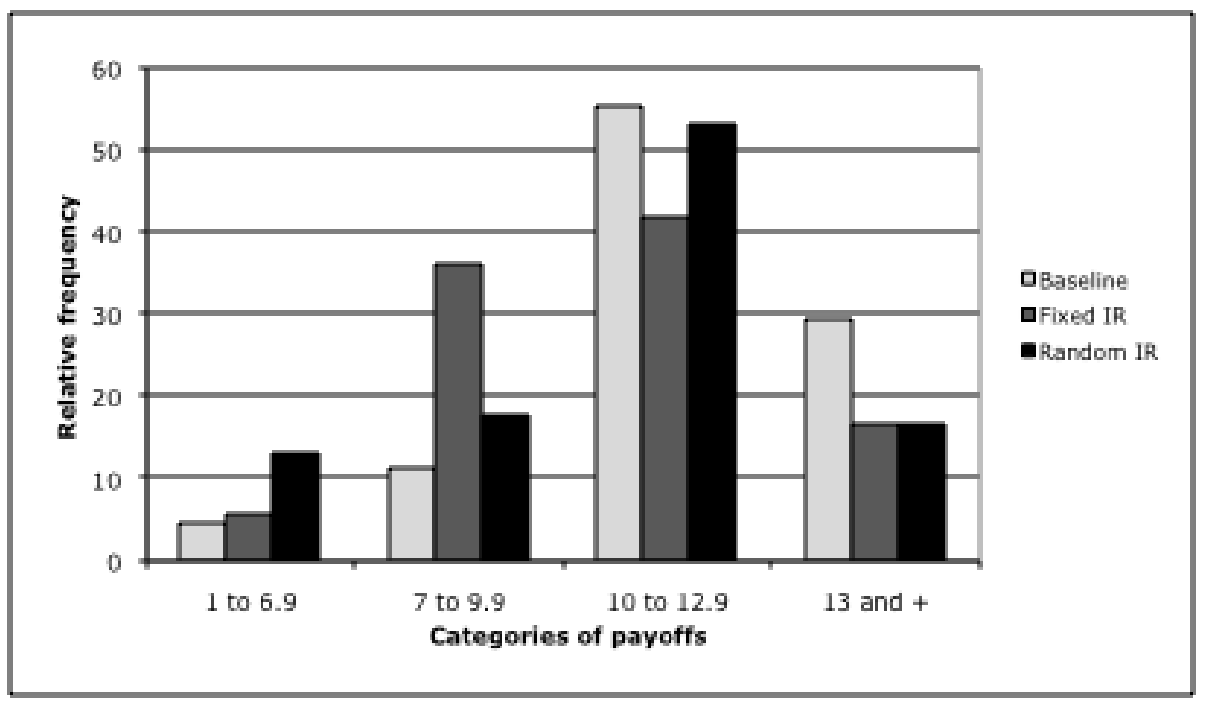

Fig.4. Distribution of the relative frequency of payoff categories by treatment 


\section{APPENDIX A. Instructions for the baseline treatment}

We thank you for participating in this experiment on decision-making. You will receive a show-up fee of 4 Euros. This session consists of several independent parts. We have distributed the instructions for the first part; you will receive later the instructions for the next parts.

At the end of the session, your earnings from the various parts will be added. You will be paid individually and in cash in a separate room.

Throughout the session, it is strictly forbidden to communicate with the other participants. Your earnings only depend on your own decisions and never on the decisions of other participants.

\section{Part 1}

On the attached form, we will present you successively with two urns that contain each ten balls, either yellow or blue.

For each urn, you must make 20 successive choices between drawing a ball from the urn with replacement or earning a certain amount of money. If you draw a yellow ball from the urn, you earn $€ 5$; if you draw a blue ball from the urn, your earn $€ 0$. We propose you 20 certain possible amounts, from $€ 0.25$ to $€ 5$. For each urn, you must make a decision for each of the 20 proposals. Only one of these decisions will matter for determining your earnings in this part, as explained below.

Please indicate on the attached form for each proposed choice and for each urn if you prefer receiving the certain amount or drawing a ball from the urn.

\section{How do we determine your earnings in this part?}

At the end of the session, in the payment room, you are requested to flip a coin to determine which urn will be actually used to determine your earnings. If the side has a tail on it, the first urn will be used. If the side has a head on it, the second urn will be used.

Next, for this urn, you will randomly draw a number between 1 and 20 to determine which of your 20 decisions will matter for determining your earnings.

For this decision, if you have ticked "I choose the certain amount", we will add this amount to your other earnings from the experiment. If you have chosen to draw a ball from the urn, you will draw the ball from the selected urn. If you draw a yellow ball, $€ 5$ will be added to your other earnings from the experiment.

If you have any question regarding these instructions, please raise your hand and we will answer your questions in private. Once you have indicated all your responses on the attached form, please raise your hand and the experimenter will bring you the next instructions. 
1) The first urn contains 10 balls: 5 yellow balls and 5 blue balls. Please indicate for each of the following decisions if you prefer receiving the certain amount or drawing a ball if this urn is selected for payment at the end of the session.

\begin{tabular}{|r|l|l|}
\hline 1 & O I choose the certain amount of $€$ 0.25 & O I choose to draw a ball \\
2 & O I choose the certain amount of $€$ 0.50 & O I choose to draw a ball \\
3 & O I choose the certain amount of $€$ 0.75 & O I choose to draw a ball \\
4 & O I choose the certain amount of $€ 1$ & O I choose to draw a ball \\
5 & O I choose the certain amount of $€ 1.25$ & O I choose to draw a ball \\
6 & O I choose the certain amount of $€ 1.50$ & O I choose to draw a ball \\
7 & O I choose the certain amount of $€ 1.75$ & O I choose to draw a ball \\
8 & O I choose the certain amount of $€ 2$ & O I choose to draw a ball \\
9 & O I choose the certain amount of $€ 2.25$ & O I choose to draw a ball \\
10 & O I choose the certain amount of $€ 2.50$ & O I choose to draw a ball \\
11 & O I choose the certain amount of $€ 2.75$ & O I choose to draw a ball \\
12 & O I choose the certain amount of $€ 3$ & O I choose to draw a ball \\
13 & O I choose the certain amount of $€ 3.25$ & O I choose to draw a ball \\
14 & O I choose the certain amount of $€ 3.50$ & O I choose to draw a ball \\
15 & O I choose the certain amount of $€ 3.75$ & O I choose to draw a ball \\
16 & O I choose the certain amount of $€ 4$ & O I choose to draw a ball \\
17 & O I choose the certain amount of $€ 4.25$ & O I choose to draw a ball \\
18 & O I choose the certain amount of $€ 4.50$ & O I choose to draw a ball \\
19 & O I choose the certain amount of $€ 4.75$ & O I choose to draw a ball \\
20 & O I choose the certain amount of $€ 5$ & O I choose to draw a ball \\
\hline
\end{tabular}

2) The second urn contains 10 balls, both yellow and blue balls, but you do not know the proportion of balls of each color. Please indicate for each of the following decisions if you prefer receiving the certain amount or drawing a ball if this urn is selected for payment at the end of the session.

\begin{tabular}{|r|l|l|}
\hline 1 & O I choose the certain amount of $€$ 0.25 & O I choose to draw a ball \\
2 & O I choose the certain amount of $€$ 0.50 & O I choose to draw a ball \\
3 & O I choose the certain amount of $€$ 0.75 & O I choose to draw a ball \\
4 & O I choose the certain amount of $€ 1$ & O I choose to draw a ball \\
5 & O I choose the certain amount of $€ 1.25$ & O I choose to draw a ball \\
6 & O I choose the certain amount of $€ 1.50$ & O I choose to draw a ball \\
7 & O I choose the certain amount of $€ 1.75$ & O I choose to draw a ball \\
8 & O I choose the certain amount of $€ 2$ & O I choose to draw a ball \\
9 & O I choose the certain amount of $€ 2.25$ & O I choose to draw a ball \\
10 & O I choose the certain amount of $€ 2.50$ & O I choose to draw a ball \\
11 & O I choose the certain amount of $€ 2.75$ & O I choose to draw a ball \\
12 & O I choose the certain amount of $€ 3$ & O I choose to draw a ball \\
13 & O I choose the certain amount of $€ 3.25$ & O I choose to draw a ball \\
14 & O I choose the certain amount of $€ 3.50$ & O I choose to draw a ball \\
15 & O I choose the certain amount of $€ 3.75$ & O I choose to draw a ball \\
16 & O I choose the certain amount of $€ 4$ & O I choose to draw a ball \\
17 & O I choose the certain amount of $€ 4.25$ & O I choose to draw a ball \\
18 & O I choose the certain amount of $€ 4.50$ & O I choose to draw a ball \\
19 & O I choose the certain amount of $€ 4.75$ & O I choose to draw a ball \\
20 & O I choose the certain amount of $€ 5$ & O I choose to draw a ball \\
\hline
\end{tabular}




\section{Part 2}

[The following instructions were distributed after the participant had completed the first part]

Please do not touch your computer before having read these instructions carefully.

During this part, earnings are calculated in points, with 5 points $=1$ Euro.

\section{Description of each period}

In each period, we propose that you perform a counting task. A paragraph of several lines will be displayed on your screen. This paragraph, randomly generated, consists of French words but is meaningless. The task consists of counting the occurrence of a particular letter in this paragraph. You will be able to count the occurrence of four letters successively during the period.

In each period, you have 2 minutes to perform the task. A counter indicates continuously the remaining time. The paragraph changes in each new period and the letters can also differ.

\section{Determination of the results}

Your earnings for this part depend on the number of letters that you have counted correctly. An answer is considered as correct if it corresponds to the actual occurrence of this letter, plus or minus one. If the computer indicates that your answer is not correct, you cannot change it and you proceed to the next letter.

However, all periods are not paid. You do not know how many periods in total are paid and you do not know in advance which periods are actually paid. You are informed only a posteriori at the end of a period whether this period gave rise to payment or not. The fact that a period gives rise to payment or not is independent of your outcome. If the period gives rise to payment, each correct answer increases your earnings by 1 point [3 points in the two intermittent reinforcement treatments].

Moreover, starting a new period costs you 1 point. This means that as soon as you start a new period, one point is deducted from your earnings, whether this period gives rise to payment or not. In the first period, the cost of starting this period is deducted from your show-up fee.

\section{Training}

Before starting the first period, you can practice during two periods to familiarize yourself with the task. These practice periods are not taken into account in the calculation of your earnings. At the end of the practice periods, the first period will start automatically.

\section{End of part 2}

You are required to complete the first 15 periods. Thereafter, it is you who decide when to stop this part. In other words, there is no automatic start of a new period and the next part will start if you decide to stop the current part. At each new period, you must click either on "start a new period" or on "stop definitively". If you choose to start a new period, 1 point is deducted from your earnings and you can perform the task. When you decide to stop, you must confirm your decision. If you confirm your decision, you cannot restart the current part and you proceed to the next part.

\section{Part 3 and end of the session}

When you decide to stop part 2, the instructions for part 3 will be displayed on your screen. This part consists of several questions to which it is important to answer sincerely. Your answers are anonymous and confidential.

At the end of the session, you will be informed when you can leave the room to get paid. THANK YOU FOR REMAINING SILENT IN LEAVING THE ROOM AND NOT COMMUNICATING WITH OTHERS. Please give back the instructions to the experimenter before leaving the room.

If you have any questions regarding these instructions, please raise your hand and we will answer your questions in private.

When ready, you can start the first practice period by clicking the button "Continue" on your screen.

Thank you for not communicating any information about this experiment. 


\section{Appendix B. A Bayesian model of reinforcement}

In Tables B1 and B2 we have calculated the implications of different Bayesian models for the baseline and the fixed IR treatments, respectively. Both tables have the same structure. The first two columns specify the different periods of the task and whether or not specific periods were paid $(1=$ paid, $0=$ not paid $)$. The remaining probabilities specify Bayesian probabilities that the next period will be paid conditional on the preceding payment history.

\section{(Tables B1 and B2 about here)}

We follow the Bayesian analysis of intermittent reinforcement proposed by O'Flaherty and Komaki (1992) and use a beta-binomial model for the probability that a particular period will be paid. Operationally, assuming a diffuse beta prior distribution, this probability is given by $(s+1) /(n+2)$ where $s$ is the number of times payments have been made and $n$ represents the number of times the same prior conditions were observed. Thus, for example, when using single trials as the unit of analysis for prior conditions, $n$ represents the number of trials experienced up to that point.

We first suppose that participants update probabilities of payment using all the data observed and assume a stationary process (see third columns in Tables B1 and B2). In the baseline (Table B1), we observe that the probability after the first period is 0.67 , rises to 0.95 by period 17 , and starts to fall after period 20 reaching its lowest value of 0.57 at the end of period 35. Assuming that participants expect to earn 3 out of 4 possible points per period (the actual median performance in pooled treatments is 3.13 if one considers the 15 compulsory periods completed by all participants) and have to pay one point to enter, the decision to enter each period has a positive expected value if the probability of payment exceeds 0.33 . In this model the smallest probability we observe is 0.57 and so, barring extreme risk aversion, no-one in the baseline would be expected to exit the task before the 
end of period 35. The same reasoning can be applied to the fixed IR treatment. Here the decision to enter a period has a positive expected value if the probability of payment exceeds 0.11 . Once again, this threshold is always exceeded such that participants would be expected to enter all periods.

However, participants may also do Bayesian updating with short memories, i.e., not taking all data into account. If so, in the baseline exiting behavior can be expected after completing period 21 (last observation, see column 4 in Table B1), period 23 (last 3 observations, see column 5), period 25 (last 6 observations, see column 6), and 27 (last 10 observations, see column 7). In the fixed IR treatment, the limited memory models do not all quite provide the same qualitative picture (see columns 4 to 7 in Table B2). With the shorter memories (last and last 3 observations), participants are not expected to exit but this tendency reverses itself as the size of memory increases (last 6 and 10 observations). For the model based on the last 10 observations, participants are expected to exit after period 30 .

Finally, we consider a third approach to modeling for the fixed IR treatment (see the last column of Table B2). Here, we assume memory for all past data but that participants encode expectations based on pairs of sequences of different types of observations made. In particular, through period 20 participants should learn that the next period is only paid if the two preceding periods were not paid (and not paid if one of the two preceding periods is paid). The unit of analysis of the Bayesian updating model is therefore two successive observations. The beliefs (probabilities) captured by this model reflect the fact that every third period is paid starting in period 5 through period 20 (that is, before the probability is changed to zero). From period 22 on, however, the model breaks down because although every observation now follows two periods that were not paid, the previously reinforced rule works no longer (i.e., payment after two successive non-payments). Moreover, whereas the probability does decrease after period 22, it is still 0.32 at the end of period 35 (i.e., 
much larger than 0.11 ). In short, unless participants exit after period 20 or 21 , the model predicts continuing with the task through period 35 .

It is important to note that we have not modeled the random IR treatment. This is because the sequence of actual paid periods varied at random from participant to participant. However, since the underlying probability is the same as in the fixed IR treatment, one would expect a similar pattern of probabilities to the fixed IR case, albeit with individual variation. 
Table B1: Hypothetical probabilities for continuous treatment

Continuous Treatment

Period Paying

$\begin{array}{rl}1 & 1 \\ 2 & 1 \\ 3 & 1 \\ 4 & 1 \\ 5 & 1 \\ 6 & 1 \\ 7 & 1 \\ 8 & 1 \\ 9 & 1 \\ 10 & 1 \\ 11 & 1 \\ 12 & 1 \\ 13 & 1 \\ 14 & 1 \\ 15 & 1 \\ 16 & 1 \\ 17 & 1 \\ 18 & 1 \\ 19 & 1 \\ 20 & 1 \\ 21 & 0 \\ 22 & 0 \\ 23 & 0 \\ 24 & 0 \\ 25 & 0 \\ 26 & 0 \\ 27 & 0 \\ 28 & 0 \\ 29 & 0 \\ 30 & 0 \\ 31 & 0 \\ 32 & 0 \\ 33 & 0 \\ 34 & 0 \\ 35 & 0 \\ & 1 \\ 13\end{array}$

$1=$ paid

$0=$ not paid
Probabilities of payment based on:

\begin{tabular}{|c|c|c|c|c|}
\hline $\begin{array}{l}\text { All previous } \\
\underline{\text { data }}\end{array}$ & $\begin{array}{l}\frac{\text { Last }}{\text { observation }} \\
\underline{\text { obse }}\end{array}$ & $\frac{\text { Last } 3}{\text { observations }}$ & $\begin{array}{l}\frac{\text { Last } 6}{\text { observations }} \\
\underline{\text { obs }}\end{array}$ & $\frac{\text { Last } 10}{\text { observations }}$ \\
\hline 0.67 & 0.67 & $x$ & $x$ & $x$ \\
\hline 0.75 & 0.67 & $x$ & $x$ & $x$ \\
\hline 0.80 & 0.67 & 0.80 & $x$ & $x$ \\
\hline 0.83 & 0.67 & 0.80 & $x$ & $x$ \\
\hline 0.86 & 0.67 & 0.80 & $x$ & $x$ \\
\hline 0.88 & 0.67 & 0.80 & 0.88 & $x$ \\
\hline 0.89 & 0.67 & 0.80 & 0.88 & $x$ \\
\hline 0.90 & 0.67 & 0.80 & 0.88 & $x$ \\
\hline 0.91 & 0.67 & 0.80 & 0.88 & $x$ \\
\hline 0.92 & 0.67 & 0.80 & 0.88 & 0.92 \\
\hline 0.92 & 0.67 & 0.80 & 0.88 & 0.92 \\
\hline 0.93 & 0.67 & 0.80 & 0.88 & 0.92 \\
\hline 0.93 & 0.67 & 0.80 & 0.88 & 0.92 \\
\hline 0.94 & 0.67 & 0.80 & 0.88 & 0.92 \\
\hline 0.94 & 0.67 & 0.80 & 0.88 & 0.92 \\
\hline 0.94 & 0.67 & 0.80 & 0.88 & 0.92 \\
\hline 0.95 & 0.67 & 0.80 & 0.88 & 0.92 \\
\hline 0.95 & 0.67 & 0.80 & 0.88 & 0.92 \\
\hline 0.95 & 0.67 & 0.80 & 0.88 & 0.92 \\
\hline 0.95 & 0.67 & 0.80 & 0.88 & 0.92 \\
\hline 0.91 & $\underline{0.33}$ & 0.60 & 0.75 & 0.83 \\
\hline 0.88 & $\underline{0.33}$ & 0.40 & 0.63 & 0.75 \\
\hline 0.84 & $\underline{0.33}$ & $\underline{0.20}$ & 0.50 & 0.67 \\
\hline 0.81 & $\overline{0.33}$ & 0.20 & 0.38 & 0.58 \\
\hline 0.78 & 0.33 & 0.20 & $\underline{0.25}$ & 0.50 \\
\hline 0.75 & $\underline{0.33}$ & $\underline{0.20}$ & $\underline{0.13}$ & 0.42 \\
\hline 0.72 & $\underline{0.33}$ & $\underline{0.20}$ & $\underline{0.13}$ & $\underline{0.33}$ \\
\hline 0.70 & $\underline{0.33}$ & 0.20 & $\underline{0.13}$ & $\underline{0.25}$ \\
\hline 0.68 & $\underline{0.33}$ & $\underline{0.20}$ & $\underline{0.13}$ & $\underline{0.17}$ \\
\hline 0.66 & 0.33 & 0.20 & 0.13 & 0.08 \\
\hline 0.64 & $\underline{0.33}$ & 0.20 & $\underline{0.13}$ & $\underline{0.08}$ \\
\hline 0.62 & $\underline{0.33}$ & $\underline{0.20}$ & $\underline{0.13}$ & $\underline{0.08}$ \\
\hline 0.60 & $\underline{0.33}$ & $\underline{0.20}$ & $\underline{0.13}$ & $\underline{0.08}$ \\
\hline 0.58 & $\underline{0.33}$ & $\underline{0.20}$ & $\underline{0.13}$ & $\underline{0.08}$ \\
\hline 0.57 & 0.33 & 0.20 & 0.13 & $\underline{0.08}$ \\
\hline
\end{tabular}

Probabilities equal to or less than 0.33 are underlined. 
Table B2: Hypothetical probabilities for fixed IR treatment

\begin{tabular}{|c|c|}
\hline Period & Paying \\
\hline 1 & 0 \\
\hline 2 & 1 \\
\hline 3 & 0 \\
\hline 4 & 0 \\
\hline 5 & 1 \\
\hline 6 & 0 \\
\hline 7 & 0 \\
\hline 8 & 1 \\
\hline 9 & 0 \\
\hline 10 & 0 \\
\hline 11 & 1 \\
\hline 12 & 0 \\
\hline 13 & 0 \\
\hline 14 & 1 \\
\hline 15 & 0 \\
\hline 16 & 0 \\
\hline 17 & 1 \\
\hline 18 & 0 \\
\hline 19 & 0 \\
\hline 20 & 1 \\
\hline 21 & 0 \\
\hline 22 & 0 \\
\hline 23 & 0 \\
\hline 24 & 0 \\
\hline 25 & 0 \\
\hline 26 & 0 \\
\hline 27 & 0 \\
\hline 28 & 0 \\
\hline 29 & 0 \\
\hline 30 & 0 \\
\hline 31 & 0 \\
\hline 32 & 0 \\
\hline 33 & 0 \\
\hline 34 & 0 \\
\hline 35 & 0 \\
\hline & $1=$ paid \\
\hline
\end{tabular}

Probabilities of payment based on:

All previous
data

0.33

0.50

0.40

0.33

0.43

0.38

0.33

0.40

0.36

0.33

0.38

0.36

0.33

0.38

0.35

0.33
0.37

0.35

0.33

0.36

0.36
0.35
0.33

0.33

0.32

0.31

0.30

0.29

0.28

0.27

0.26

0.25

0.24

0.23

0.23
0.22
0.22
Last

observation

Last 3

observations

$x$

0.40

0.40

0.40

0.40

0.40

0.40

0.40

0.40

0.40

0.40

0.40

0.40

0.40

0.40

0.40

0.40

0.40

0.40

0.40

0.40

0.20

0.20

0.20

0.20

0.20

0.20

0.20

0.20

0.20

0.20

0.20

0.20

0.20
Last 6

observations

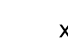

$x$
$x$
$x$

$x$
$x$

$x$
0.38

0.38

0.38

0.38

0.38
0.38

0.38

0.38

0.38

0.38

0.38

0.38

0.38

0.38

0.38

0.38

0.38

0.25

0.25

0.25

0.13

0.13

0.13

0.13

0.13

0.13

0.13

0.13

0.13

0.13
Last 10

observations

Sequences of

$\underline{2 \text { observations }}{ }^{1}$

\begin{tabular}{rr}
$x$ & $x$ \\
$x$ & 0.33 \\
$x$ & 0.33 \\
$x$ & 0.67 \\
$x$ & 0.25 \\
$x$ & 0.25 \\
$x$ & 0.75 \\
$x$ & 0.20 \\
0.33 & 0.20 \\
0.42 & 0.80 \\
0.33 & 0.17 \\
0.33 & 0.17 \\
0.42 & 0.83 \\
0.33 & 0.14 \\
0.33 & 0.14 \\
0.42 & 0.86 \\
0.33 & 0.13 \\
0.33 & 0.13 \\
0.42 & 0.88 \\
0.33 & $\underline{0.11}$ \\
0.33 & $\underline{0.11}$ \\
0.33 & 0.78 \\
0.25 & 0.70 \\
0.25 & 0.64 \\
0.25 & 0.58 \\
0.17 & 0.54 \\
0.17 & 0.50 \\
0.17 & 0.47 \\
$\underline{0.08}$ & 0.44 \\
$\underline{0.08}$ & 0.41 \\
\hline 0.08 & 0.39 \\
$\underline{0.08}$ & 0.37 \\
\hline 0.08 & 0.35 \\
& 0.33 \\
\hline 0.35 & 0.32 \\
\hline & \\
\hline 0 &
\end{tabular}

${ }^{1}$ There are three sequence types

not paid, paid

paid, not paid

not paid, not paid 